\title{
Latest Permian carbonate carbon isotope variability traces heterogeneous organic carbon accumulation and authigenic carbonate formation
}

\author{
Martin Schobben ${ }^{1,2}$, Sebastiaan van de Velde ${ }^{3}$, Jana Gliwa ${ }^{2}$, Lucyna Leda ${ }^{2}$, Dieter Korn ${ }^{2}$, Ulrich Struck ${ }^{2,4}$, \\ Clemens Vinzenz Ullmann ${ }^{5}$, Vachik Hairapetian ${ }^{6}$, Abbas Ghaderi ${ }^{7}$, Christoph Korte ${ }^{8}$, Robert J. Newton ${ }^{1}$, \\ Simon W. Poulton ${ }^{1}$, and Paul B. Wignall ${ }^{1}$ \\ ${ }^{1}$ School of Earth and Environment, University of Leeds, Woodhouse Lane, Leeds, LS2 9JT, UK \\ ${ }^{2}$ Museum für Naturkunde, Leibniz-Institut für Evolutions- und Biodiversitätsforschung, \\ Invalidenstr. 43, 10115 Berlin, Germany \\ ${ }^{3}$ Analytical, Environmental and Geochemistry, Vrije Universiteit Brussel, Pleinlaan 2, 1050 Brussels, Belgium \\ ${ }^{4}$ Institut für Geologische Wissenschaften, Freie Universität Berlin, Malteserstr. 74-100, 12249 Berlin, Germany \\ ${ }^{5}$ College of Engineering, Mathematics and Physical Sciences, Camborne School of Mines, University of Exeter, \\ Penryn Campus, Penryn, Cornwall TR10 9FE, UK \\ ${ }^{6}$ Department of Geology, Esfahan (Khorasgan) Branch, Islamic Azad University, P.O. Box 81595-158, Esfahan, Iran \\ ${ }^{7}$ Department of Geology, Faculty of Sciences, Ferdowsi University of Mashhad, Azadi Square, 9177948974, Mashhad, Iran \\ ${ }^{8}$ Department of Geosciences and Natural Resource Management, University of Copenhagen, \\ Øster Voldgade 10, 1350 Copenhagen, Denmark
}

Correspondence to: Martin Schobben (m.schobben@leeds.ac.uk, schobbenmartin@gmail.com)

Received: 4 May 2017 - Discussion started: 11 May 2017

Revised: 19 September 2017 - Accepted: 16 October 2017 - Published: 22 November 2017

\begin{abstract}
Bulk-carbonate carbon isotope ratios are a widely applied proxy for investigating the ancient biogeochemical carbon cycle. Temporal carbon isotope trends serve as a prime stratigraphic tool, with the inherent assumption that bulk micritic carbonate rock is a faithful geochemical recorder of the isotopic composition of seawater dissolved inorganic carbon. However, bulk-carbonate rock is also prone to incorporate diagenetic signals. The aim of the present study is to disentangle primary trends from diagenetic signals in carbon isotope records which traverse the Permian-Triassic boundary in the marine carbonate-bearing sequences of Iran and South China. By pooling newly produced and published carbon isotope data, we confirm that a global first-order trend towards depleted values exists. However, a large amount of scatter is superimposed on this geochemical record. In addition, we observe a temporal trend in the amplitude of this residual $\delta^{13} \mathrm{C}$ variability, which is reproducible for the two studied regions. We suggest that (sub-)sea-floor microbial communities and their control on calcite nucleation and ambient porewater dissolved inorganic
\end{abstract}

carbon $\delta^{13} \mathrm{C}$ pose a viable mechanism to induce bulk-rock $\delta^{13} \mathrm{C}$ variability. Numerical model calculations highlight that early diagenetic carbonate rock stabilization and linked carbon isotope alteration can be controlled by organic matter supply and subsequent microbial remineralization. A major biotic decline among Late Permian bottom-dwelling organisms facilitated a spatial increase in heterogeneous organic carbon accumulation. Combined with low marine sulfate, this resulted in varying degrees of carbon isotope overprinting. A simulated time series suggests that a $50 \%$ increase in the spatial scatter of organic carbon relative to the average, in addition to an imposed increase in the likelihood of sampling cements formed by microbial calcite nucleation to 1 out of 10 samples, is sufficient to induce the observed signal of carbon isotope variability. These findings put constraints on the application of Permian-Triassic carbon isotope chemostratigraphy based on whole-rock samples, which appears less refined than classical biozonation dating schemes. On the other hand, this signal of increased carbon isotope variability concurrent with the largest mass extinction of the Phanerozoic may pro- 
vide information about local carbon cycling mediated by spatially heterogeneous (sub-)sea-floor microbial communities under suppressed bioturbation.

\section{Introduction}

Carbon isotopes in carbonate rock are a pivotal tool for understanding the ancient biogeochemical carbon cycle and a stratigraphic aid in determining the age of sedimentary deposits. Individual fossil carbonate shells are the preferred recorder of the isotope composition of marine dissolved inorganic carbon (DIC). However, some deposits, such as those of Precambrian age or those which were formed during biotic crises or where shelly fossils are absent, are not suitable for such a single-component approach (Veizer et al., 1999; Prokoph et al., 2008). Under these circumstances, bulk-rock samples are a widely used alternative recorder (Saltzman, 2001; Brand et al., 2012a, b). This approach has attracted criticism due to the complex multicomponent nature and high potential for diagenetic alteration, which may result in a mixture of primary and secondary diagenetic signals. Major sources of contamination that are known to affect the primary marine carbon isotope signal of bulk-carbonate rock are degradation of organic matter and methane oxidation (Marshall, 1992; Reitner et al., 2005; Wacey et al., 2007; Birgel et al., 2015).

Carbonate sediments are especially prone to chemical alteration during early compaction and lithification when the highly porous sediment and unstable carbonate polymorphs (e.g., aragonite and high-Mg calcite) are subjected to cementation and dissolution (Bathurst, 1975; Irwin et al., 1977; Marshall, 1992). The potential for diagenetic alteration of biogenic high-Mg calcite and aragonite results from elevated substitution of foreign ions in the lattice and a higher degree of dislocations (Busenberg and Plummer, 1989).

On carbonate platforms subjected to rapid sea level fluctuations, lithification might be controlled by interaction with meteoric fluids and oxidized terrestrial organic matter (Brand and Veizer, 1980, 1981; Banner and Hanson, 1990; Knauth and Kennedy, 2009). The latter mode of carbonate rock cementation with allochthonous dissolved carbonate sources (meteoric water) in a relatively open system has long been viewed as the predominant process of carbonate rock stabilization (Bathurst, 1975). These notions were fuelled by an over-representative focus on Pleistocene carbonate platforms (e.g., the Bahamas) and their associated diagenetic stabilization under the influence of glacial-interglacial-induced sea level fluctuations (James and Choquette, 1983). However, this mechanism is less relevant for rock lithified under greenhouse conditions when sea level changes are dampened (Bathurst, 1993; Munnecke and Samtleben, 1996; Melim et al., 2002).

Alternatively, carbonate rock alteration is driven by marine-derived fluids that evolved through interaction with precursor sediments and ambient chemical conditions (Munnecke and Samtleben, 1996; Melim et al., 2002). Foremost, the reactive and biologically active upper section of the sediment column can be envisioned as leaving an imprint on carbonate chemistry, including the carbon isotope composition. This carbon isotope signal will be retained in postdepositional carbonate cements and is controlled by organic carbon (OC) fluxes, $\mathrm{pH}$, alkalinity and the nature of the (sub-)sea-floor microbial communities (Melim et al., 2002; Reitner et al., 2005; Wacey et al., 2007; Birgel et al., 2015; Schobben et al., 2016; Zhao et al., 2016).

A more nuanced view on the nature of bulk-rock carbon isotope composition would be to envision diagenetic overprinting on carbonate rock chemistry as a spectrum where pure primary and strictly diagenetic end-member states are considered as a continuum, with bulk-rock chemistry falling somewhere in between these two extremes (Marshall, 1992). In this case, the aim should be to discern the degree to which an original imprint could have been retained in the bulk-rock signal. Embracing both ends of this spectrum could illuminate new aspects of marine sedimentary systems and ancient ocean chemistry, as well as providing a more refined understanding of the mechanisms that promote the diagenetic alteration of carbonate sediments. Clear examples of the importance of interpreting diagenetic signals have been given by the assertion that authigenic carbonate production might play a primary role in the global biogeochemical carbon cycle (Schrag et al., 2013) and in the isotopic imprint of terrestrial biomass on Precambrian carbonates (Knauth and Kennedy, 2009).

\section{Background: Permian-Triassic carbonate carbon isotope records}

Temporal trends in carbonate carbon isotope composition have been recorded at varying timescales from million-year secular trends (Veizer et al., 1999; Zachos et al., 2001) to dramatic sub-million-year events, such as at the PaleoceneEocene Thermal Maximum (Dickens et al., 1995). The sedimentary record of the Permian-Triassic $(\mathrm{P}-\mathrm{Tr})$ boundary interval, marked by the largest mass extinction of the Phanerozoic (Erwin, 1993; Alroy et al., 2008), is also characterized by pronounced carbon isotope excursions, which are almost exclusively recorded in bulk rock. However, chemical signatures from this time period include records with a wide variety of amplitudes and shapes and span centimetres to metres of rock sequence (e.g., Xie et al., 2007; Korte et al., 2010). Equally diverse are the proposed drivers of these geochemical signals, ranging from prolonged episodes of volcanism and the eustasy-controlled erosion of organic-rich shelf sediments to abrupt blooms of methane-producing microbes (Renne et al., 1995; Berner, 2002; Rothman et al., 2014). 
Variable-amplitude carbon isotope excursions in shelf to basin transects have been linked to an intensified biological pump (Meyer et al., 2011; Song et al., 2013). This notion contrasts with the viewpoint of collapsed primary productivity (or a "Strangelove" ocean) as a driver for the demise of bottom-dwelling and infaunal marine biota (Rampino and Caldeira, 2005). The loss of these geobiological agents resulted in a reduced thickness of the sedimentary mixed layer and a global increase in the occurrence of laminated sediments (Wignall and Twitchett, 1996; Hofmann et al., 2015). Contrary to disrupted primary productivity, these geological features would also agree with a scenario of enhanced OC remineralization and resulting widespread marine deoxygenation (Meyer et al., 2008, 2011). These contrasting scenarios of global-scale environmental deterioration are difficult to reconcile. Nevertheless, the reduction of sediment mixing is an unequivocal feature that warrants consideration when interpreting P-Tr chemical records.

An elevated oceanic carbonate inventory is a predicted aspect of an ocean without pelagic calcifiers, which only started proliferating during the Mesozoic and would effectively buffer short-term perturbations to P-Tr marine carbon isotopes (Kump and Arthur, 1999; Zeebe and Westbroek, 2003; Rampino and Caldeira, 2005; Ridgwell, 2005; Payne et al., 2010). This does not, however, exclude local departures from this dynamic equilibrium or depth-related isotope differences, such as those forced by the biological pump (Kump and Arthur, 1999; Rampino and Caldeira, 2005). High carbonate ion concentrations are invoked to explain the advent of (microbial) carbonate sea-floor structures (e.g., thrombolites, stromatolites and fan-shaped structures) in the extinction aftermath and the ensuing Early Triassic recovery phase (Baud et al., 1997; Rampino and Caldeira, 2005; Riding and Liang, 2005; Pruss et al., 2006; Kershaw et al., 2007, 2009; Leda et al., 2014). While conditions favoured the formation of these structures, poorly buffered calcified metazoans (e.g., brachiopods and corals) were proportionally more affected by the end-Permian mass extinction (Knoll et al., 2007). This biotic shift has been interpreted as a prevalent carbonate factory turnover from skeletal to microbial (e.g., Kershaw et al., 2009).

A carbonate factory turnover, reduced sediment mixing and increased OC sinking fluxes invite consideration of a scenario in which these individual parameters act as synergistic effects on carbonate formation and diagenetic stabilization. Moreover, the imprint of ${ }^{12} \mathrm{C}$-depleted carbon on latest Permian carbonate rock produced by the introduction of authigenic carbonate has been connected to a systematic carbon isotope offset between bulk rock and brachiopod shells (Schobben et al., 2016). Diagenetic and authigenic carbonate sources can, however, result in a range of carbon isotope values relating to the specific microbial community and sedimentary environment (Irwin et al., 1977). Hence, we hypothesize that spatial carbon isotope variability at the $\mathrm{P}-\mathrm{Tr}$ boundary interval relates to an increased importance of mi- crobially controlled calcite nucleation. Moreover, we postulate that organic carbon sinking fluxes and subsequent in situ remineralization by microbes determine the trajectory of carbonate rock stabilization. Combined geographic differences in the OC sinking fluxes ( $\mathrm{km}$ scale) and sediment mixing $(\mathrm{cm}$ scale) might have generated spatially heterogeneous dispersion of organic carbon. This spatial pattern of OC distribution links to observed carbonate carbon isotope variability by modulating the chance of sampling variable isotope signals along lateral lithological transects. We adopt this conceptual model as a working hypothesis for interpreting stratigraphic carbon isotope patterns in $\mathrm{P}-\mathrm{Tr}$ carbonate rock. In addition, however, this scenario likely has implications for the interpretation of bulk-rock carbon isotope patterns during other periods of the Precambrian and Phanerozoic.

To carry out this investigation, we studied carbonatebearing sequences of Permian to Triassic strata located in Iran and China using a compilation of published and new data. The effect of microbial metabolism on sediments and porewater can be numerically approximated by reactive transport models (Soetaert et al., 1996; Boudreau, 1997; Meysman et al., 2003; van de Velde and Meysman, 2016). Similarly, diagenetic models have proven useful in delineating trajectories of bulk-rock $\mathrm{Sr}$ and $\mathrm{Ca}$ isotope stabilization (Fantle and DePaolo, 2006, 2007). For the purpose of our study, we will combine aspects of these models in an effort to estimate the potential for the microbially mediated spatial modification of bulk-rock carbon isotope signals.

\section{Materials and methods}

\subsection{Bulk-carbonate carbon isotope records}

\subsubsection{Material selection and stable carbon isotope measurements}

The $\mathrm{P}-\mathrm{Tr}$ limestone sequences of Iran are particularly suited to study spatial $\delta^{13} \mathrm{C}_{\text {carb }}$ variations, as lateral lithological homogeneity excludes a strong control from palaeoceanographic conditions or selective preservation potential (see the Supplement). In addition to the classical P-Tr sites of Shahreza, Zal and Ali Bashi in Iran, we sampled several other sites for which we present the first $\delta^{13} \mathrm{C}_{\text {carb }}$ results. These sites include the Aras Valley profile $\left(39.015^{\circ} \mathrm{N}, 45.434^{\circ} \mathrm{E}\right)$ about $19 \mathrm{~km} \mathrm{WNW}$ of the towns of Dzhulfa (Azerbaijan) and Julfa (Iran), four parallel sections in the Baghuk Mountains (section A: $31.563^{\circ} \mathrm{N}, 52.438^{\circ} \mathrm{E}$; section 1: $31.567^{\circ} \mathrm{N}, 52.444^{\circ} \mathrm{E}$; section C: $31.567^{\circ} \mathrm{N}, 52.443^{\circ} \mathrm{E}$; section $\left.\mathrm{J}: 31.565^{\circ} \mathrm{N}, 52.441^{\circ} \mathrm{E}\right) 50 \mathrm{~km} \mathrm{NNW}$ of Abadeh and $140 \mathrm{~km}$ SSE of Esfahan and the Asadabad succession $\left(31.848^{\circ} \mathrm{N}, 52.181^{\circ} \mathrm{E}\right)$. Limestone, marlstone and calcareous shale $\left(>20 \% \mathrm{CaCO}_{3}\right.$ ) beds were collected bed by bed. Powder aliquots were produced by micro-drilling fresh rock surfaces to avoid sampling of obvious late diagenetic calcite veins and weathered surfaces. 
A total of 463 stable carbon isotope measurements were made at the University of Copenhagen (UC) and the $\mathrm{Mu}$ seum für Naturkunde (MfN), Berlin. Glass reaction vessels $\left(\mathrm{Labco}^{\circledR}\right)$ containing the sample powders were flushed with helium, and carbonate was left to react with 50 (UC) or 30 (MfN) $\mu \mathrm{L}$ of anhydrous phosphoric acid $(\sim 102 \%)$ for at least $1.5 \mathrm{~h}$. Carbon and oxygen isotope values were measured from resulting $\mathrm{CO}_{2}$ using an Isoprime triple collector isotope ratio mass spectrometer in continuous-flow setup (UC) or a Thermo Finnigan Gasbench (GS) II linked to a Thermo Finnigan MAT V isotope ratio mass spectrometer (IRMS; MfN). Pure $\mathrm{CO}_{2}(99.995 \%)$ calibrated against international IAEA standards (NSB-18 and NSB-19) was used as a reference gas. At the UC, results were corrected for weightdependent isotope ratio bias using multiple measurements of an in-house standard LEO (Carrara marble; $\delta^{13} \mathrm{C}=1.96 \%$ ) covering the entire range of signal intensities encountered in the samples. External reproducibility was monitored through the replicate analysis of the in-house standards LEO and Pfeil STD (Solnhofen limestone) at the UC and MfN, respectively. Long-term accuracy was better than $0.1 \%$ ( $2 \mathrm{SD}$; better than $0.2 \% 2 \mathrm{SD}$ for oxygen isotopes). All carbon isotope values are reported in \%o relative to VPDB and in standard $\delta$ notation.

\subsubsection{Complementary data collection}

Our new data are complemented by published bulk-carbonate $\delta^{13} \mathrm{C}$ data from multiple $\mathrm{P}-\mathrm{Tr}$ localities in Central Iran (Abadeh (Heydari et al., 2000; Korte et al., 2004a; Horacek et al., 2007; Korte et al., 2010; Liu et al., 2013), Shahreza (Korte et al., 2004b; Heydari et al., 2008; Richoz et al., 2010) and north-western Iran (Ali Bashi mountains and Zal; Baud et al., 1989; Korte et al., 2004c; Korte and Kozur, 2005; Kakuwa and Matsumoto, 2006; Horacek et al., 2007; Richoz et al., 2010; Schobben et al., 2016). For a more global perspective and a comparative approach, we additionally extracted published data from the P-Tr Global Boundary Stratotype Section and Point (GSSP) at Meishan, China (Baud et al., 1989; Chen et al., 1991; Xu and Yan, 1993; Hoffman et al., 1998; Jin et al., 2000; Cao et al., 2002; Gruszczyński et al., 2003; Zuo et al., 2006; Kaiho et al., 2006; Huang et al., 2007; Riccardi et al., 2007; Xie et al., 2007). Data were extracted from tables and supplementary files or provided by the authors and where necessary read from figures with the open-source software xyscan (Ullrich, 2016). This compilation adds 2077 data points to our new dataset. The analytical uncertainty of the collected data, when given, ranges between 0.02 and $0.2 \%$. We included replicate studies on the same site, as these data are potentially valuable assets to test the reproducibility of stable isotope investigations and to shed light on the effect of the bulk-rock multicomponent nature on $\delta^{13} \mathrm{C}_{\text {carb }}$ composition.

\subsubsection{Data projection}

To facilitate a direct comparison of $\delta^{13} \mathrm{C}_{\text {carb }}$ between different sites with differences in total sediment thickness, we converted the stratigraphic height to a dimensionless timeline. This approach preserves a more direct connection to the sampled rock sequence rather than converting to absolute ages or maintaining original stratigraphic heights. The conversion to a dimensionless time grid was carried out by using the lower and upper bounds of individual conodont assemblage biozones as tie points to which a relative distance for an individual $\delta^{13} \mathrm{C}_{\text {carb }}$ data point is assigned (see the Supplement). The chronological scheme used here divides the $\mathrm{P}-\mathrm{Tr}$ interval into biostratigraphic units (A-K), which enables the correlation of individual sequences in both geographic regions (Table 1).

To evaluate trends in the collected data, a sliding window with a bandwidth equivalent to the dimensionless grid unit has been applied to the $\delta^{13} \mathrm{C}_{\text {carb }}$ data. This method ensures the extraction of temporal trends at equivalent time resolution to the biozonation units (Fig. 1).

To cancel out the potential for an uneven spread of data points, we also applied a subsampling routine on the Iranian and Chinese datasets. Subsampling was performed with the sliding window procedure, as described above, before applying summary statistics. Subsequently, the median values were calculated for each of the subsampled $\delta^{13} \mathrm{C}_{\text {carb }}$ populations. For simplification, the resulting median trend line and $95 \%$ confidence intervals (CIs) are calculated and visually weighted (Fig. 2) (visually weighted plot or watercolour regression; Hsiang, 2012; Schönbrodt, 2012). The latter is accomplished by calculating a kernel density, and both the drawn median trend line and CI interval are weighted by colour saturation based on this kernel density value. In addition, the median trend line and the $\mathrm{CI}$ interval have been assigned contrasting colours to further enforce the visual signal. Hence, saturated and contrasting parts of the depicted regression curve (i.e., sections with high visual weight) depict areas with the highest fidelity of the temporal geochemical pattern based on the subsampling routine. In addition to the median trend lines, the same subsampling approach and visual weighting has been applied to calculate and plot the interquartile range (IQR; the value range containing $50 \%$ of the sample population) and $95 \%$ interpercentile range (IPR; the value range containing $95 \%$ of the sample population). Graphs are plotted with the open-source programming platform R (R Core Team, 2016) and with the aid of the R packages; ggplot2 (Wickham, 2009), reshape2 (Wickham, 2007), plyr (Wickham, 2011) and gridExtra (Auguie, 2016). 
Table 1. Correlative biostratigraphic units.

\begin{tabular}{lll}
\hline Unit & Iran & China $^{\text {a }}$ \\
\hline $\mathrm{K}$ & Neospathodus dieneri & Stepanovites kummeli \\
$\mathrm{J}$ & Hindeodus postparvus & Clarkina tulongensis-Clarkina planata \\
$\mathrm{I}$ & Isarcicella isarcica & Isarcicella isarcica \\
& Isarcicella staeschei & Isarcicella staeschei \\
$\mathrm{H}$ & Hindeodus lobata & \\
& Hindeodus parvus & Hindeodus parvus \\
$\mathrm{G}$ & Merrillina ultima-Stepanovites mostleri & \\
& Hindeodus praeparvus-Hindeodus changxingensis & Hindeodus changxingensis \\
$\mathrm{F}$ & Clarkina hauschkei & \\
& Clarkina abadehensis & Clarkina meishanensis \\
$\mathrm{E}$ & Clarkina yini & Clarkina yini \\
& Clarkina nodosa & \\
& Clarkina bachmanni & Clarkina changxingensis \\
$\mathrm{D}$ & Clarkina changxingensis & Clarkina wangi-Clarkina subcarinata \\
$\mathrm{C}$ & Clarkina subcarinata & Clarkina orientalis \\
$\mathrm{B}$ & Clarkina orientalis & \\
$\mathrm{A}$ & Clarkina trancaucasica & \\
& Clarkina leveni & \\
\hline
\end{tabular}

${ }^{a}$ Meishan P-Tr GSSP. See the Supplement file for references regarding the biostratigraphy studies considered to construct this biozonation scheme.

\subsection{Reactive transport modelling}

\subsubsection{Geochemical model formulation and biogeochemical reactions}

Organic matter availability fuels in situ metabolic pathways linked to calcite nucleation. Upon entering the sediment, organic matter is microbially mineralized, which is coupled to the reduction of electron acceptors. These electron acceptors are consumed in a well-defined sequence based on their thermodynamic energy yield: $\mathrm{O}_{2}, \mathrm{SO}_{4}^{2-}$ and methanogenesis (Berner, 1964; Froelich et al., 1979). Each of these microbial metabolisms will imprint a specific carbon isotope signature on the porewater DIC and thus create a potential source for diagenetic alteration of carbonate $\mathrm{C}$ isotope signatures (Irwin et al., 1977).

These mineralization processes can be described by mass balance equations (Eqs. 1 and 2), which can subsequently be solved numerically via the method of lines (Boudreau, 1996; Soetaert and Meysman, 2012). The numerical solutions of these equations solve the age-depth $(t$ and $z$ ) relationship of deposited sediments in terms of solids $\left(S_{i}\right)$, solutes $\left(C_{i}\right)$ in pore fluids and their respective reactions between the solid and liquid phase. At the top of the sediment pile the porewaters communicate with ocean water so that dissolved elements can diffuse according to their concentration gradients. In addition to diffusion transport processes, continued sedimentation supplies the sediment with organic carbon and calcium carbonate.

$$
\begin{aligned}
\varphi \frac{\partial C_{i}}{\partial t} & =\frac{\partial}{\partial z}\left(\varphi D_{i} \frac{\partial C_{i}}{\partial z}-\varphi v C_{i}\right) \\
& +\sum_{k} v_{i, k} R_{k}+\varphi \alpha(z)\left(C_{o w}-C(z)\right) \\
(1-\varphi) \frac{\partial S_{i}}{\partial t} & =\frac{\partial}{\partial z}\left((1-\varphi) D_{b}(z) \frac{\partial S_{i}}{\partial z}-(1-\varphi) w S_{i}\right) \\
& +\sum_{k} v_{i, k} R_{k}
\end{aligned}
$$

In Eqs. (1) and (2), $\varphi$ is porosity, $D_{i}$ is the effective diffusion coefficient and $D_{b}$ and $\alpha(z)$ are parameters associated with bioturbation (see below); $v_{i, k}$ is the stoichiometric coefficient of species $C_{i}$ in reaction $R_{k}$. Note that we express reactions as mol per unit time per volume sediment and concentrations as mol per volume porewater or volume solid phase. Therefore $\varphi$ and 1- $\varphi$ are introduced as unit conversions. The model includes three different modes of transport: sedimentation (represented by downward advection of solutes $v$ and solids $w$ ), molecular diffusion and biological transport (bioturbation). Since we only consider cohesive sediments, the only advective transport is burial; i.e., new sediment is added on top of the sediment column, and sediment at the bottom of the column is buried (transported out of the column). Molecular diffusion for porewater solutes is expressed by Fick's first law, where $D_{i}$ (the effective diffusion coefficient) is calculated following the definition as given in Boudreau and Meysman (2006).

$D_{i}=\frac{D_{0}}{(1-2 \ln \varphi)}$ 
(a)

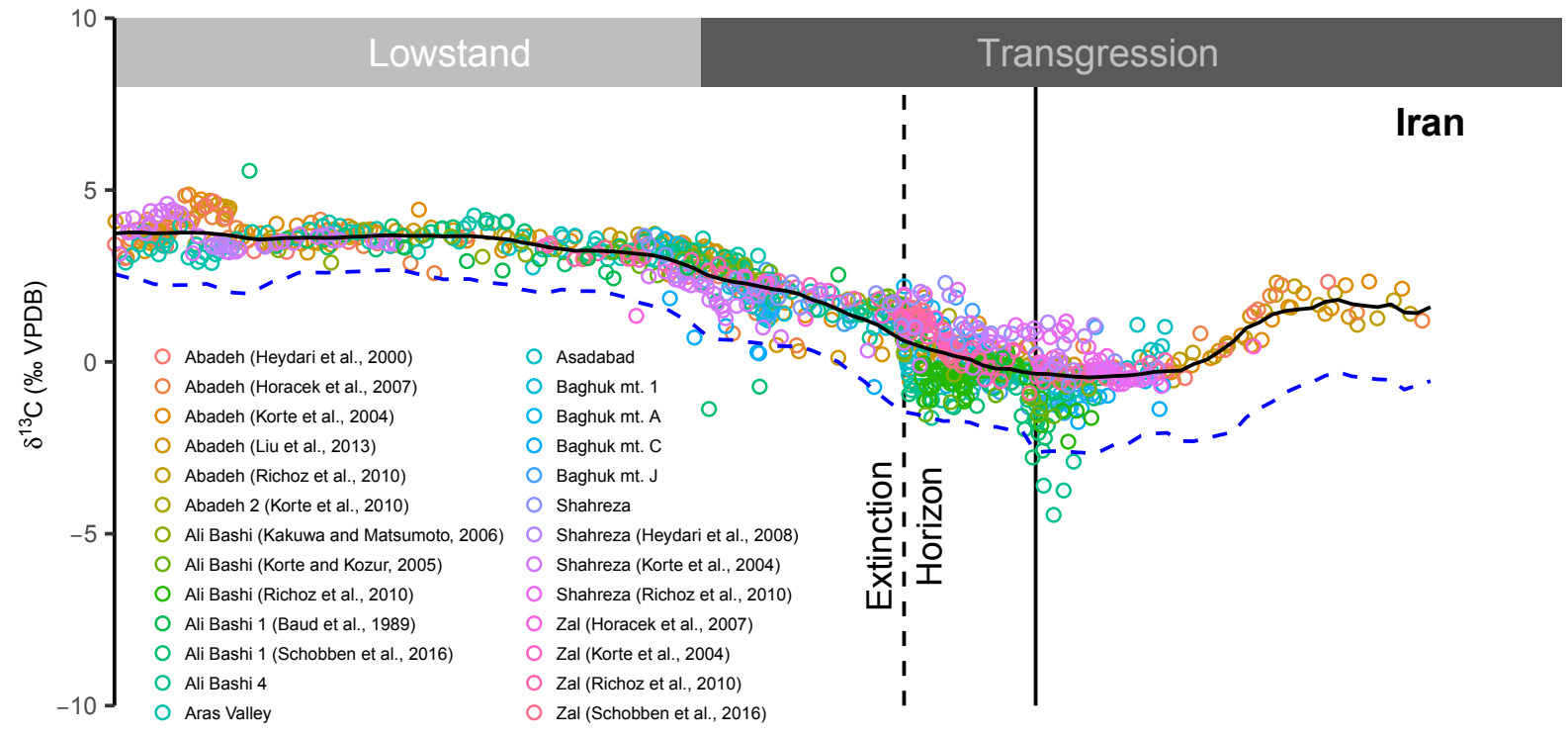

(b)

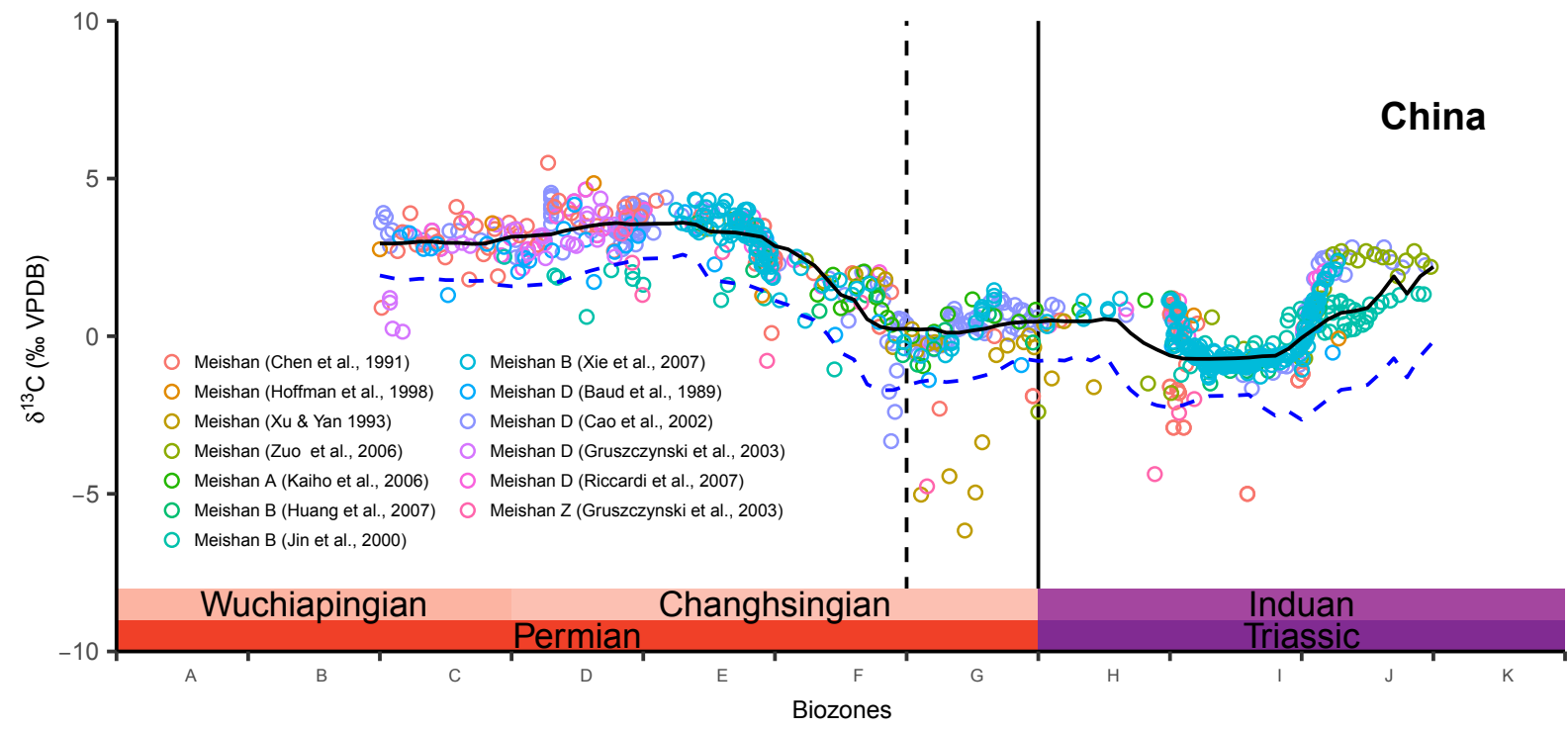

Figure 1. Compiled published and new data for multiple P-Tr rock sequences in Iran (a) and China (b). The individual carbonate carbon isotope values are placed on a dimensionless timeline that marries both geographic areas in the most acceptable biochronological scheme (Table 1). The solid black line represents the subsampled median trend line. The dashed blue line depicts the seawater $\delta^{13} \mathrm{C}_{\mathrm{DIC}}$ curve as obtained from the time series simulation (Sect. 5). The stratigraphic placement of the sea level changes and the extinction horizon as well as the biostratigraphic framework can be found in the Supplement.

where $D_{0}$ is a function of temperature and salinity and has been calculated with the $\mathrm{R}$ package marelac (Soetaert et al., 2016). Bioturbation is implemented as two separate processes: bio-mixing and bio-irrigation (Kristensen et al., 2012) following conventional descriptions (Boudreau, 1984; Meysman et al., 2010). The bio-mixing is modulated over the depth interval to account for the effects of sediment reworking by metazoans in the top layer of the sediment pile. In this formulation it is assumed that $D_{\mathrm{b}}$ remains constant in a layer with thickness $z_{\mathrm{b}}$, after which it attenuates with depth by following an exponential relation with coefficient $\lambda_{D_{\mathrm{b}}}$ and background bio-diffusivity $\left(D_{\mathrm{b} 0}\right)$ at the seawater-sediment 
(a)

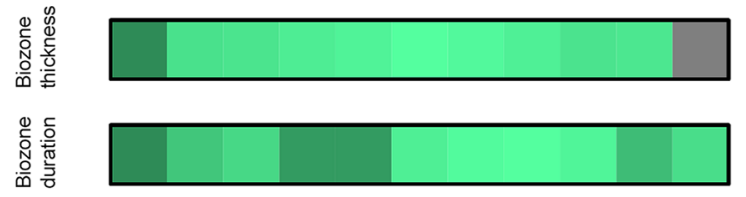

$$
\text { 言 }
$$

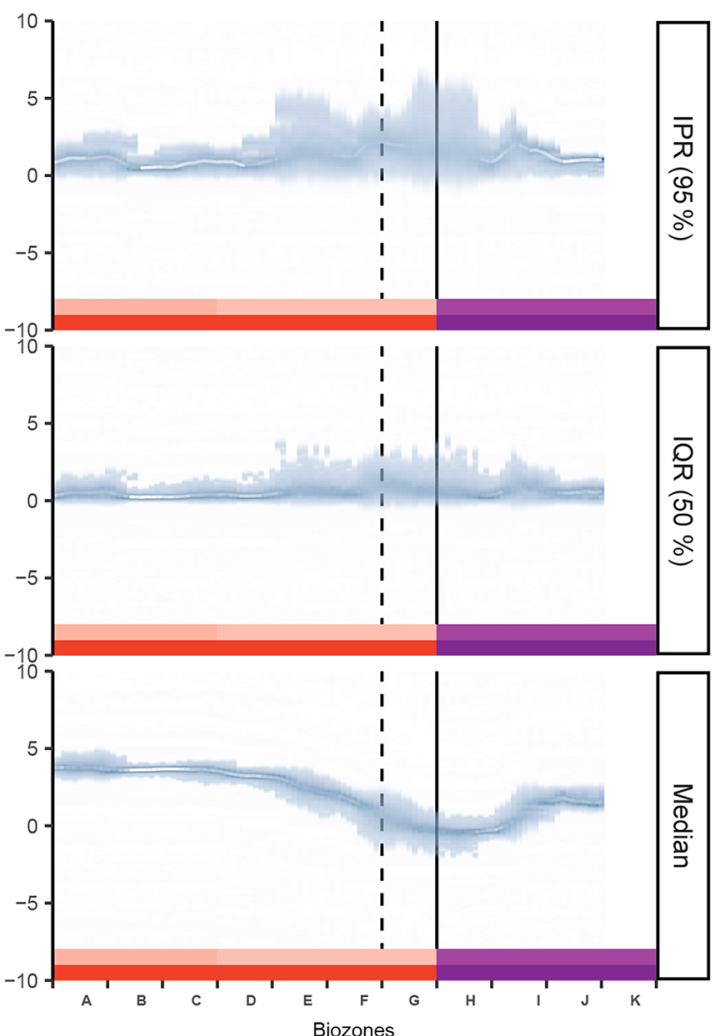

(b)
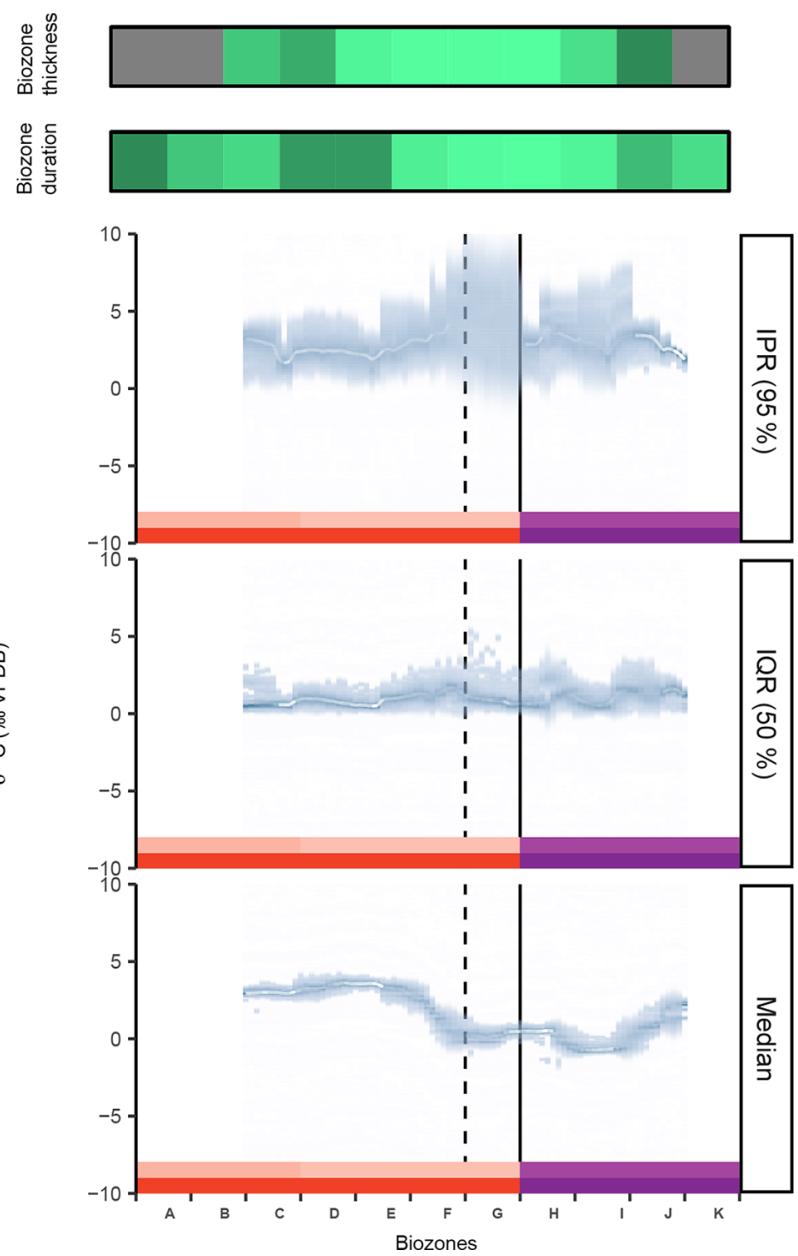

Figure 2. Visually weighted data plot for the Iranian (a) and South China (b) P-Tr (sub)localities (Sect. 3.1.3) depicting the median trend line, the IQR $(50 \%)$ and the IPR $(95 \%) \delta^{13} \mathrm{C}$ value ranges. Trends with lowest fidelity are marked by a blurring of colours and less contrasted colours (based on the CI of multiple subsample routines). The dashed and the solid line represent the extinction horizon and P-Tr boundary, respectively. The saturation level of the green tiles in the upper two panels equals a more extended biozone thickness $(0.12-32.00 \mathrm{~m})$ and longer duration $(0.02-1.00 \mathrm{My})$. Grey tiles represent intervals with no available biostratigraphic data. See Fig. 1 for colour legend of the stratigraphic units.

interface (Soetaert et al., 1996).

$D_{\mathrm{b}}(z)=D_{\mathrm{b} 0}$

for $z \leq z_{b}$

and

$D_{\mathrm{b}}(z)=D_{\mathrm{b} 0} \exp \left(\frac{-\left(z-z_{\mathrm{b}}\right)}{\lambda_{D_{\mathrm{b}}}}\right) \quad$ for $z>z_{\mathrm{b}}$

Bio-irrigation exchanges porewater with the overlying water via burrow flushing. This is implemented via a non-local exchange process (Boudreau, 1984).

$I_{\text {irr }}(z)=\alpha(z)\left(C_{o w}-C(z)\right)$

The quantity $\alpha(z)$ represents the depth-dependent irrigation intensity, and the solute concentrations of the bottom water and at depth are given by $C_{o w}$ and $C(z)$, respectively. The attenuation of bio-irrigation is expressed by an exponential relation

$\alpha(z)=\alpha_{0} \exp \left(-\frac{z}{x_{\text {irr }}}\right)$

In this formulation, $\alpha_{0}$ is the irrigation coefficient at the sediment-water interface, and $x_{\text {irr }}$ is the attenuation depth coefficient. Most of the macrofaunal activity takes place in the upper few centimetres of the sediment (as animals are dependent on food resources that rain down via the water column). Therefore, both bio-mixing and bio-irrigation processes are most intense near the sediment-water interface.

The aim of this model is to give a parsimonious description of the potential effect of early diagenetic reactions on the isotope signature of carbonates. Therefore, we do not consider nitrification or metal cycling, as this would increase the complexity of the model and calculations; in addition, this would not fundamentally alter our conclusions. Organic mat- 
Table 2. Biogeochemical reaction equations and kinetic rate expressions.

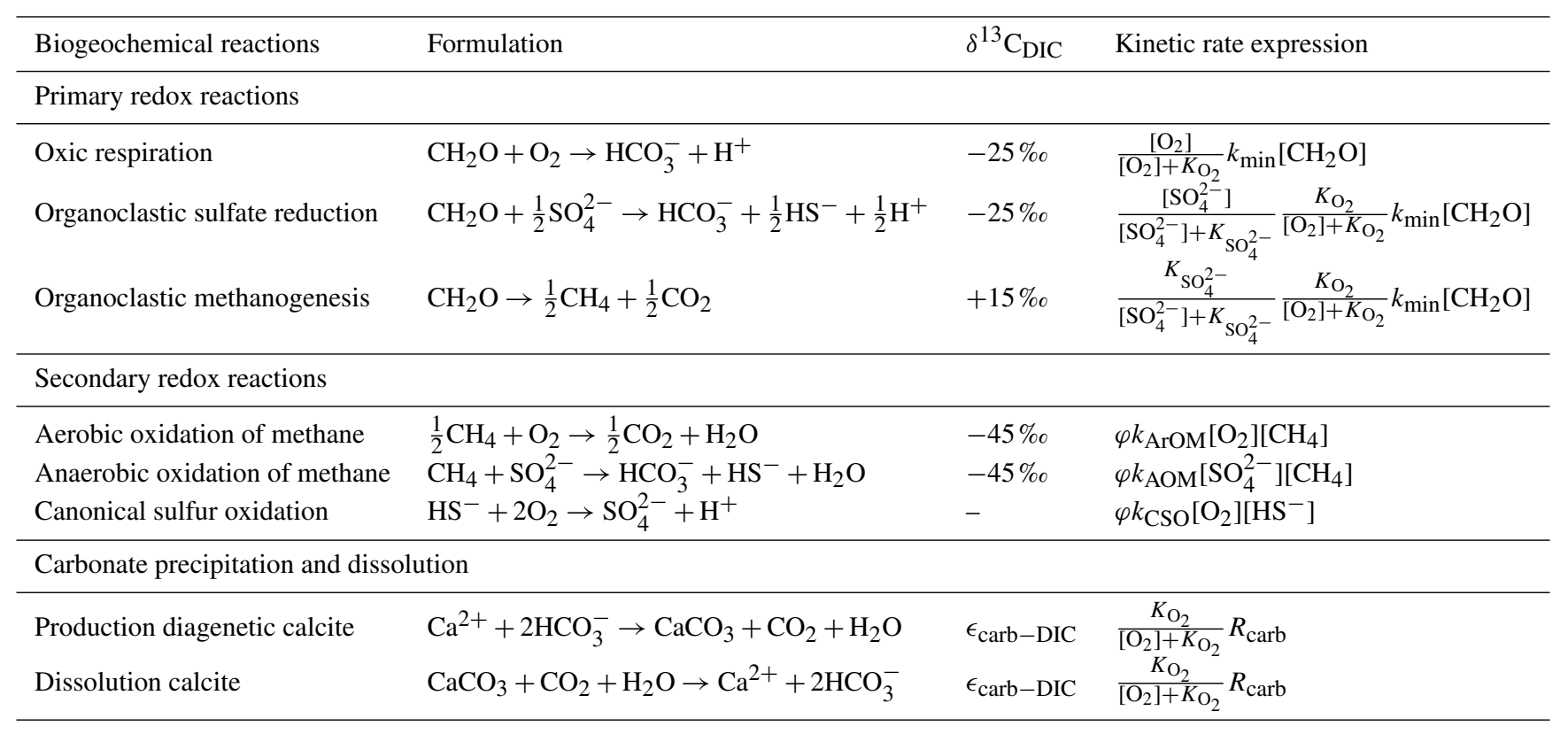

Metabolism-produced carbon isotope values according to (Irwin et al., 1977), except organoclastic methanogenesis-sourced $\mathrm{CH}_{4}$ subsequently employed by AOM and ArOM, which is a conservative estimate between $-65 \%$ and near-quantitative sedimentary OC conversion to $\mathrm{CH}_{4}$, thereby approaching the parent $\mathrm{OC}-\mathrm{C}$ isotope composition of $-25 \%$.

ter can be mineralized via different pathways: aerobic respiration, sulfate reduction and organoclastic methanogenesis (in which organic matter acts both as electron donor and acceptor; Table 2). The reduction of sulfate produces sulfide, which can be oxidized by oxygen via canonical sulfide oxidation (CSO) (Meysman et al., 2003; van de Velde and Meysman, 2016). Methanogenesis produces methane, which can be oxidized by sulfate in a process called anaerobic oxidation of methane (AOM) or by oxygen (ArOM) (Boetius et al., 2000). The mineralization reactions are expressed via standard limitation-inhibition formulations (Soetaert et al., 1996). The Monod constants $\left(K_{\mathrm{O}_{2}}\right.$ and $\left.K_{\mathrm{SO}_{4}^{2-}}\right)$ in these formulations determine the inhibition or limitation of a certain electron acceptor. For example, at high concentrations of oxygen, oxygen reduction will be efficient and other mineralization pathways will be inhibited. At lower concentrations, oxygen reduction will be less efficient, and other pathways will gain importance (Soetaert et al., 1996; Van Cappellen and Wang, 1996; Berg et al., 2003; Meysman et al., 2003). This sequential alternation of limitation and subsequent inhibition of metabolic pathways results in chemical zonation of the sediment profile (Froelich et al., 1979). The reoxidation reactions are given as second-order rate laws in which the kinetic constants $\left(k_{\mathrm{ArOM}}, k_{\mathrm{AOM}}\right.$ and $\left.k_{\mathrm{CSO}}\right)$ determine the reaction rate of the respective reactions (Table 2; Boudreau, 1997; Meysman et al., 2003).

To mimic calcium carbonate recrystallization following an age-depth relationship, dissolution and carbonate production reaction rates, expressed as Eq. (7), have been incorporated in the model with no net carbonate dissolution or precipitation
(Fantle and DePaolo, 2006, 2007).

$R_{\mathrm{carb}}(t)=\frac{0.4}{f_{\mathrm{dia}}} \exp \left(-\frac{t}{0.876 f_{\mathrm{dia}}}\right)$

In contrast to the models of Fantle and DePaolo (2006, 2007) we envision that only a fraction of the whole carbonate rock determines the reactivity towards dissolution and recrystallization. This fraction of 0.2 is considered to be the diagenetic carbonate fraction ( $\left.f_{\text {dia }}\right)$ of the total rock volume (e.g., Schobben et al., 2016). Specific metabolically produced DIC $\delta^{13} \mathrm{C}$ values are assigned for organoclastic microbial sulfate reduction, AOM and organoclastic methanogenesis (see Table 2). These metabolic pathways have been considered to induce calcite nucleation by changing the surrounding carbonate chemistry, forming an organic matrix or destroying calcification-inhibiting organic mucus (Berner et al., 1970; Visscher et al., 2000; Arp et al., 2001; Ries et al., 2008; Heindel et al., 2013; Birgel et al., 2015). The peak activity of these metabolic pathways coincides with the most reactive upper layers of the sediment column, i.e., highly porous and high metastable calcite polymorph content (Irwin et al., 1977; Marshall, 1992); this is mathematically expressed by Eq. (7).

Solute diffusion tracts and the sedimentation of the carbon isotopes of DIC and solid-phase carbonate are defined as ${ }^{13} \mathrm{C}$ and ${ }^{12} \mathrm{C}$, respectively, and are calculated separately. Metabolically introduced carbon ( $\left.v_{\text {metabolism }}\right)$ by reaction $\left(R_{k}\right)$ and its respective effect on porewater DIC carbon isotope composition is formulated by Eqs. (8) and (9) for the heavy and light 
isotope, respectively.

$v_{\text {metabolism }}=R_{k} \frac{1}{1+r_{k}}$

$v_{\text {metabolism }}=R_{k} \frac{r_{k}}{1+r_{k}}$

We assign a ${ }^{13} \mathrm{C} /{ }^{12} \mathrm{C}$ ratio $(r)$ to the metabolism-specific produced DIC from the organic carbon remineralization reactions according to the data in Table 2. The mathematical formulation of metabolism-introduced DIC ensures that the isotope composition of ambient porewater DIC is altered and ensures mass balance in the model carbon input and output.

\subsubsection{Numerical solutions and parameters}

The model includes nine state variables: organic matter $\left(\mathrm{CH}_{2} \mathrm{O}\right)$, solid carbonate $\left({ }^{13} \mathrm{C}_{\text {carb }}\right.$ and $\left.{ }^{12} \mathrm{C}_{\text {carb }}\right)$, DIC $\left({ }^{13} \mathrm{C}_{\text {DIC }}\right.$ and $\left.{ }^{12} \mathrm{C}_{\text {DIC }}\right)$, dissolved oxygen $\left(\mathrm{O}_{2}\right)$, dissolved sulfate $\left(\mathrm{SO}_{4}^{2-}\right)$, dissolved methane $\left(\mathrm{CH}_{4}\right)$ and dissolved sulfide $\left(\mathrm{HS}^{-}\right)$. We numerically solved Eqs. (1) and (2) on the opensource programming platform R (R Core Team, 2016) with a finite difference approach by expanding the spatial derivatives of partial differential equations over a sediment grid (Boudreau, 1997). Through the application of the R package ReacTran (Soetaert and Meysman, 2012), a sediment grid $10 \mathrm{~m}$ thick with 20000 layers of identical thicknesses was generated. The finite difference approach transforms the partial differentials into ordinary differentials which are subsequently integrated by a stiff solver routine vode (Brown and Hindmarsh, 1989) within the R package DeSolve (Soetaert et al., 2010). Boundary conditions were chosen to reflect Permian oceanic conditions based on the current state of research (Sect. 2) and complemented by current knowledge of shallow marine environments. The upper boundary conditions were set to concentrations for normal modern bottom water conditions: $0.28 \mu \mathrm{mol} \mathrm{cm}{ }^{-3} \mathrm{O}_{2}$ and zero for the reduced species $\left(\mathrm{CH}_{4}\right.$ and $\left.\mathrm{HS}^{-}\right)$. A lower seawater $\mathrm{SO}_{4}^{2-}$ value of $4 \mu \mathrm{mol} \mathrm{cm}{ }^{-3}$ (compared to the modern value of $28 \mu \mathrm{mol} \mathrm{cm}^{-3}$ ) was chosen based on evidence of a reduced global marine $\mathrm{S}$ reservoir in the latest Permian to Early Triassic (Luo et al., 2010; Song et al., 2014; Schobben et al., 2017). On the other hand, DIC was set at $4.5 \mu \mathrm{mol} \mathrm{cm} \mathrm{c}^{-3}$ (higher than the modern value of $2.2 \mu \mathrm{mol} \mathrm{cm}{ }^{-3}$ ) based on model calculations of a Late Permian ocean without pelagic calcifiers (Ridgwell, 2005). The solid phases entering the model at the top of the sediment stack are set at $730 \mu \mathrm{mol} \mathrm{cm}{ }^{-2} \mathrm{yr}^{-1}$ for both the OC flux $\left(F_{\mathrm{OC}}\right)$ and the carbonate flux $\left(F_{\text {carb }}\right)$ in the baseline model, which are typical average shelf sedimentation values (Müller and Suess, 1979; Reimers and Suess, 1983; Sarmiento and Gruber, 2004). For the baseline condition, sedimentation rates ( $v$ and $w)$ are fixed at $0.2 \mathrm{~cm} \mathrm{yr}^{-1}$ and the $\delta^{13} \mathrm{C}$ composition is set at $+5 \%$ o (VPDB) based on primary carbon isotope values from pristine preserved brachiopod calcite from the Ali Bashi and Meishan sections, as well as sites in northern Italy (Korte et al., 2005; Brand et al., 2012b; Schobben et al., 2014). For the bio-mixing and bio-irrigation parameters, the values for the Palaeozoic proposed by Dale et al. (2016) were chosen: $D_{\mathrm{b} 0}=5 \mathrm{~cm}^{2} \mathrm{yr}^{-1}, z_{\mathrm{b}}=2 \mathrm{~cm}, \alpha_{0}=50 \mathrm{yr}^{-1}, x_{\text {irr }}=1 \mathrm{~cm}$. This will approximate the sedimentary conditions of a sea floor inhabited by a Permian benthic community. The relation between the isotope composition of DIC and solid-phase carbonate is given by the following thermodynamic relation (Eq. 10) established by Emrich et al. (1970) in which we assume temperature $(T)$ to be constant at $25^{\circ} \mathrm{C}$.

$\epsilon_{\mathrm{carb}-\mathrm{DIC}}=1.85+0.035\left[T\left({ }^{\circ} \mathrm{C}\right)-20\right]$

The lower boundary conditions for both solid and solute species were set at a "no gradient" boundary to ensure that materials are only transported by burial to deeper parts of the sediment column. The kinetic parameters are summarized in Table 3 and are based on published models.

\subsubsection{Bulk-carbonate carbon isotope signal imprinting and its sensitivity towards environmental parameters}

The previously defined parameters provide a baseline model to test the sensitivity towards certain boundary conditions in bringing forward carbon isotope compositional changes in the porewaters. Two pathways of carbonate rock formation and stabilization are considered to be of importance in capturing these porewater carbon isotope compositional changes.

1. The first is diagenetic carbonate alteration, which is envisioned as ongoing recrystallization and dissolution with depth after burial, as formulated in Eq. (7), and with both processes operating in equilibrium (Fantle and DePaolo, 2006, 2007). Under this mechanism carbonate is constantly exchanged between the solid (carbonate precipitate) and aqueous phase (porewater DIC) with ongoing burial, thereby to some degree buffering the isotopic perturbations caused by microbial mineralization. This pathway of carbonate sediment progression can be viewed as the classical interpretation of limestone stabilization: dissolution of less stable components and subsequent occlusion of the produced pore spaces by cements (Bathurst, 1993; Munnecke and Samtleben, 1996; Melim et al., 2002).

2. The second is authigenic carbonate addition, which is regarded to be a process of near-instantaneous precipitation of carbonate crusts at (or close to) the sea floor by microbial mat communities. The latter mechanism would simulate the sea-floor crust formation commonly observed for the $\mathrm{P}-\mathrm{Tr}$ transition, which is recognized as 
Table 3. Parameter values for the kinetic constants of the reactive transport model.

\begin{tabular}{|c|c|c|c|c|}
\hline Constant & Symbol & Unit & Value & Reference \\
\hline \multicolumn{5}{|l|}{ Organic matter reduction } \\
\hline Decay constant for organic matter & $k_{\min }$ & $\mathrm{yr}^{-1}$ & 0.1 & $\mathrm{a}$ \\
\hline Monod constant oxygen consumption & $K_{\mathrm{O}_{2}}$ & $\mu \mathrm{mol} \mathrm{cm}^{-3}$ & 0.001 & $\mathrm{~b}$ \\
\hline Monod constant sulfate reduction & $K_{\mathrm{SO}_{4}^{2-}}$ & $\mu \mathrm{mol} \mathrm{cm}{ }^{-3}$ & 0.9 & $\mathrm{~b}$ \\
\hline \multicolumn{5}{|l|}{ Oxidation reactions } \\
\hline Kinetic constant ArOM & $k_{\mathrm{ArOM}}$ & $\mu \mathrm{molcm}^{-3} \mathrm{yr}^{-1}$ & $10^{4}$ & $\mathrm{c}$ \\
\hline Kinetic constant AOM & $k_{\mathrm{AOM}}$ & $\mu \mathrm{mol} \mathrm{cm}{ }^{-3} \mathrm{yr}^{-1}$ & $10^{4}$ & $\mathrm{c}$ \\
\hline Kinetic constant canonical sulfur oxidation & $k_{\mathrm{CSO}}$ & $\mu \mathrm{mol} \mathrm{cm}{ }^{-3} \mathrm{yr}^{-1}$ & $10^{4}$ & $\mathrm{~b}$ \\
\hline
\end{tabular}

References: a: Fossing et al. (2004); b: Meysman et al. (2015); c: Contreras et al. (2013)

a time of unusual carbonate sedimentation; e.g., stromatolites, thrombolites and microbially induced cementation (Baud et al., 1997; Woods et al., 1999; Leda et al., 2014). However, the mechanism directly responsible for this type of biologically induced calcification is ambiguous and might be related to extracellular polymeric substances and the orientation of functional groups on this organic matrix (creating nucleation sites), destruction of organic compounds that inhibit calcification or a direct consequence of metabolism and associated changes in ambient carbonate chemistry (Visscher et al., 2000; Arp et al., 2001; Bundeleva et al., 2014). We further assume that cryptic forms of carbonate precipitates, e.g., rock-binding cements (e.g., Richoz et al., 2010), might have escaped detection when selecting carbonate rock for carbon isotope studies.

These two pathways are henceforward referred to as diagenetic carbonate alteration and authigenic carbonate addition, respectively. Note that porewater chemistry and its control on carbonate formation are not explicitly formulated in the model and are instead expressed by a reaction rate that can vary with age (Eq. 7) (Fantle and DePaolo, 2006, 2007). This formulation is justifiable due to the uncertainties in the ultimate control of biological activity in steering calcification, as cited above.

Diagenetic carbonate alteration is determined by taking the evolved solid-phase $\delta^{13} \mathrm{C}$ at $10 \mathrm{~m}$ of sediment depth where carbon isotope exchange between porewater and solid carbonate reaches equilibrium (see also Fantle and DePaolo, 2006, 2007, for a comparative $\mathrm{Sr}$ and $\mathrm{Ca}$ isotope equilibrium with depth). Although transient seawater chemistry changes can occur over the time needed to complete carbonate stabilization (i.e., before reaching equilibrium at $10 \mathrm{~m}$ of depth), we consider the adopted isotope value to be a good approximation of a partially recrystallized carbonate rock, as diffusion and the majority of metabolic processes are confined to only a small interval of the sediment column (upper $\sim 1 \mathrm{~m}$ of the sediment pile). Authigenic carbonate addi- tion is regarded to take place in the upper $0.1 \mathrm{~m}$ of the sediment column through precipitation from porewater DIC that is most severely perturbed by metabolic activity and largely unbuffered by exchange with carbonate sediments through dissolution and recrystallization. The evolved bulk-rock carbon isotope value is then calculated by using the mass balance of the primary and authigenic carbonate $\left(f_{\text {auth }}\right)$ components.

An important parameter inducing changes in the vertical structure of a diagenetic redox profile, and ultimately carbonate carbon isotope composition during carbonate rock formation and stabilization, is the $F_{\mathrm{OC}}$. By systematically changing this parameter we test the sensitivity of the diagenetic baseline model to the OC sinking flux and the consequential organic matter remineralization trajectories, i.e., the dominant microbial communities involved in local in situ C-cycling. The effect of the OC sedimentary regime on the carbonate isotope system is probed by looking at the $\mathrm{C}$ isotope offset, the primary carbonate precipitate (settling through the water column) and the bulk-rock end-member $\left(\Delta^{13} \mathrm{C}_{\text {primary-bulk }}\right)$. In addition to the OC flux, we performed sensitivity experiments for the sedimentation rate ( $w$ and $v$ ), the concentrations of bottom water DIC and sulfate and the fraction of diagenetic and/or authigenic carbonate $\left(f_{\text {dia }}\right.$ and/or $\left.f_{\text {auth }}\right)$ incorporated in the bulk rock. For each separate sensitivity experiment we return the changing parameter to the initial value, as defined for the baseline model (Sect. 3.2.2), except for the parameter of interest and the OC flux. In addition, we tested the influence of bio-diffusion $\left(D_{\mathrm{b} 0}\right)$ and bioirrigation $\left(\alpha_{0}\right)$ under varying depth profiles of sediment mixing on $\Delta^{13} C_{\text {primary-bulk }}$.

\section{Results}

\subsection{First-order temporal trends}

By compiling $\delta^{13} \mathrm{C}_{\text {carb }}$ data and unifying them in a biochronological framework, we can distinguish first-order 
temporal features of the combined Iranian and the Meishan P-Tr (sub-)localities in China (Fig. 1). The subsampling routine prevents modifications through unequal sampling intensity; hence this temporal pattern is unbiased by the sampling strategy applied in individual studies. A gradual decline towards $4 \%$ lower $\delta^{13} \mathrm{C}_{\text {carb }}$ can be discerned starting from the middle Changhsingian, with minimum values $(0 \%)$ reached in the earliest Triassic and a return to $2 \%$ higher $\delta^{13} \mathrm{C}_{\text {carb }}$ commencing above the I. isarcica zone (unit I). Nonetheless, disparity in regional trends is visible as a double-peaked negative excursion marking the $\mathrm{P}-\mathrm{Tr}$ transitional beds of Meishan, whereas such a signature is absent in time-equivalent boundary beds deposited at the Iranian sites.

By comparing the combined subsampled median trend lines of individual studies (constructed following the same statistical routine as outlined in Sect. 3.1.3), it is possible to determine whether the first-order isotope trend is a consistent feature of the analysed stratigraphic sequences. A large portion of the compared individual datasets is marked with a high coefficient of determination $\left(r^{2}\right.$; Fig. 3$)$. We can conclude that the geochemical signal obtained is reproducible and, as such, observable in rock collected during separate sampling campaigns over several decades. However, the comparative study also suggests that the correlation coefficients are consistently weaker in the Meishan data relative to the Abadeh data. This lack of reproducibility might stem from limited stratigraphic coverage; see Gruszczyński et al. (2003), who report on a composite dataset of two sublocalities, Meishan D and Z, only encompassing Changhsingian strata. Sampling campaigns of reduced stratigraphic coverage might not be able to capture the first-order trend. Nevertheless, region-specific differences in signal reproducibility mark an overall greater disparity between individual Meishan $\delta^{13} \mathrm{C}_{\text {carb }}$ records and might point to a higherorder of $\delta^{13} \mathrm{C}$ variability.

\subsection{Residual carbon isotope variability}

Subsampled and time-sliced median interpolations are depicted in Fig. 2. Trends with the highest confidence are highlighted by a well-defined white line, and the width of the $\mathrm{CI}$ is represented by a blue colour that becomes less intense with increasing data spread. Combined, these graphing features result in a more blurred image with a larger spread between the median values of individual subsampling routines (Sect. 3.1.3). From these figures we can discern three features in the second-order $\delta^{13} \mathrm{C}$ excursions: (1) the residual $\delta^{13} \mathrm{C}$ variability is seemingly random or stochastic and defined $\delta^{13} \mathrm{C}$ excursions are unreproducible across lithological successions from different geographic locations (Iran) or studies targeting the same site (e.g., Meishan section; Fig. 1). (2) There is a returning temporal pattern towards decreased fidelity of the median trend line (blurred white trend line) connected with increased $\mathrm{CI}$ dispersion (i.e., residual $\delta^{13} \mathrm{C}$ variability seen as less saturated blue colour tones) across the extinction horizon and ranging into the Early Triassic at both geographic locations. Increased maximum $\delta^{13} \mathrm{C}$ value ranges from less than 1 and $2 \%$ (IQR) or 2 and $3 \%$ (IPR) in the pre-extinction beds to more than 2 and $3 \%$ (IQR) or 5 and $8 \%$ (IPR) around the extinction horizon for Iran and China, respectively, further enforces the observation of a globally significant peak in residual $\delta^{13} \mathrm{C}$ variability. This pattern seems to recover after the P-Tr boundary, with generally higher confidence median trend lines and a trend to smaller maximum $\delta^{13} \mathrm{C}$ value ranges of less than 2 and $3 \%$ (IQR) or 5 and $8 \%$ (IPR) for Iran and China, respectively. (3) In addition, a significant regional offset can be discerned in $\delta^{13} \mathrm{C}$ value ranges; the Chinese profile displays systematically higher residual $\delta^{13} \mathrm{C}$ variability.

Studies focussing on boundary events (e.g., the P-Tr transition) tend to channel sampling effort at a focal point around the presumed faunal turnover and horizon of palaeoenvironmental change (Wang et al., 2014). Sampling effort is known to have a profound impact on studies that use fossil data to track animal diversity through time (Alroy et al., 2008; Mayhew et al., 2012). By correcting for sampling effects through subsampling (Sect. 3.1.3), we cancelled out the potential effect of over-representative data accumulation on the temporal trend of stochastic residual $\delta^{13} \mathrm{C}_{\text {carb }}$ variability. Sampling effort might also have affected fossil collecting, thereby biasing conodont biozonation schemes, which heavily relies on the first-appearance datum of certain fossil species (Wang et al., 2014; Brosse et al., 2016). As such, it would be conceivable that longer-duration biozones could capture a more temporally variable marine DIC $\delta^{13} \mathrm{C}$ compared to shorter-duration biozones. When evaluating the average thickness and duration of our chosen biochronological units, there is an apparent decrease in unit thickness and a shorter duration when approaching the extinction interval (Fig. 2). A comparison of biozone stratigraphic thickness and duration points to a relationship between higher $\delta^{13} \mathrm{C}_{\text {carb }}$ dispersion and smaller and shorter-duration units (Fig. 2). This inverse relationship suggests that $\delta^{13} \mathrm{C}_{\text {carb }}$ variability is not controlled by the increased potential sample size and the inherent risk of sampling a more temporally variable isotope signature. Hence, we exclude the applied sampling strategy and the biochronological framework as causal factors behind the observed temporal trend of stochastic $\delta^{13} \mathrm{C}_{\mathrm{carb}}$ variability.

\subsection{Model response to organic carbon accumulation}

In the above, we have conceptualized a model that links the sedimentation of organic material to carbonate carbon isotope alteration. An important variable in this model is the amount of organic carbon that arrives at the sea floor, which controls the redox depth profile and the respective importance of metabolic pathways as reaction per unit area. Low organic carbon fluxes $\left(500 \mu \mathrm{mol} \mathrm{cm} \mathrm{cm}^{-3} \mathrm{yr}^{-1}\right)$ yield aerobic respiration and microbial sulfate reduction as important biochemical reactions (Fig. 4). On the other hand, the impor- 

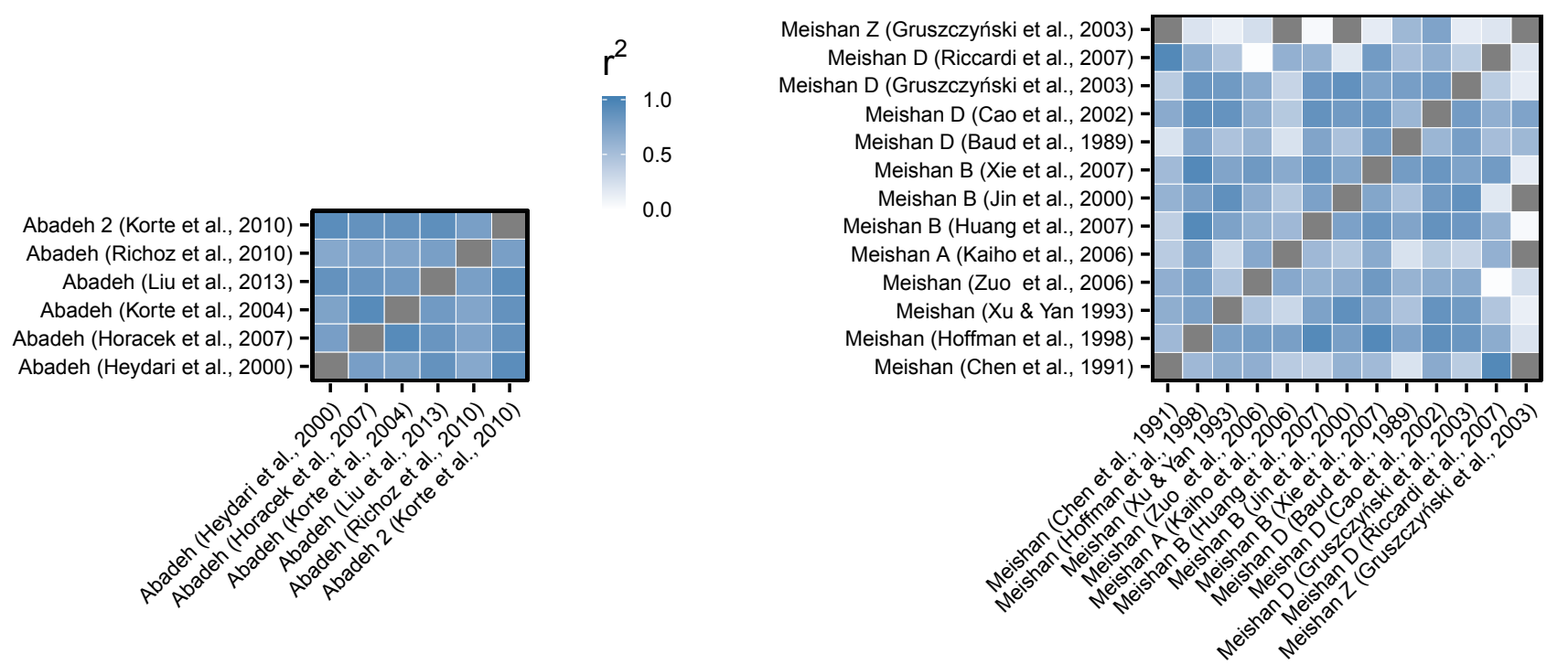

Figure 3. A comparative analysis of first-order temporal trends in $\delta^{13} \mathrm{C}_{\text {carb }}$ from individual studies for the Abadeh and Meishan (sub-)localities. The saturation level of the individual tiles measures the correlative strength of stratigraphic trends obtained during individual sampling campaigns based on the coefficient of determination $\left(r^{2}\right)$.

tance of this metabolic pathway is reduced under high OC accumulation regimes $\left(>1000 \mu \mathrm{molcm} \mathrm{cm}^{-3} \mathrm{yr}^{-1}\right)$, which are signified by intense methane production through organoclastic methanogenesis (Fig. 4). Consequently, the dominant organic carbon remineralization pathway determines the final evolved carbon isotope composition of the equilibrated bulkrock end-member, e.g., towards lower $\delta^{13} \mathrm{C}_{\text {carb }}$ under low OC accumulation and higher $\delta^{13} \mathrm{C}_{\text {carb }}$ under high $\mathrm{OC}$ loading of the sea floor (Figs. 4-6).

By systematically changing $F_{\mathrm{OC}}$ we see a defined relationship between bulk-rock $\mathrm{C}$ isotope alteration and the predominant mode of organic matter remineralization, e.g., microbial sulfate reducers, AOM or methanogenesis (Fig. 5). The sensitivity experiments further reveal that the fraction of diagenetic precipitate incorporation and bottom DIC have only a limited effect on the difference between the primary carbonate precipitate and the bulk-rock end-member $\mathrm{C}$ isotope value ( $\Delta^{13} C_{\text {primary-bulk }}$ ). In contrast, marine sulfate levels modulate the total range of observed $\delta^{13} \mathrm{C}(\sim 2-3.5 \%)$ and introduce a switch in the system, which narrows the range of $\mathrm{OC}$ accumulation over which the maximum devi-

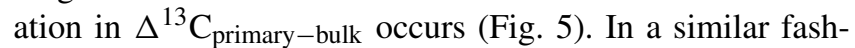
ion, elevated sedimentation ( $v$ and $w$ ) causes a shift in peak $\Delta^{13} C_{\text {primary-bulk values. However, this shift in peak values }}$ causes a modest increase in the total attained $\mathrm{C}$ isotope alteration with varying $\mathrm{OC}$ accumulation under higher sedimentation rates $(v$ and $w)$.

A systematic study of OC accumulation results in comparable trajectories of diagenetic $\mathrm{C}$ isotope modification on bulk rock through authigenic carbonate addition (Fig. 6). However, authigenic sea-floor cementation results in a $10 \%$ o range of attainable bulk-rock end-member $\mathrm{C}$ isotope values, which is a wider range than obtained for diagenetic carbonate alteration. This style of carbonate cementation is also strongly controlled by seawater sulfate concentration. Lower than modern marine dissolved sulfate values $\left(28 \mu \mathrm{mol} \mathrm{cm}{ }^{-3}\right)$ allow for a large range of $\delta^{13} \mathrm{C}$ end-member values to be generated under a smaller range of $F_{\mathrm{OC}}$ (Fig. 6). As opposed to diagenetic carbonate alteration, heightened sedimentation ( $v$ and $w$ ) only causes a shift in the switch from positive to negative $\Delta{ }^{13} \mathrm{C}_{\text {primary-bulk }}$ in the end-member rock but does not change the total range of $\mathrm{C}$ isotope alteration. However, both elevated bottom water DIC and a decreased size of the authigenic fraction diminishes the maximum range of $\Delta^{13} \mathrm{C}_{\text {primary-bulk. }}$.

Both bio-mixing and bio-irrigation by pre-extinction Permian benthic fauna $\left(D_{\mathrm{b} 0}=5 \mathrm{~cm}^{2} \mathrm{yr}^{-1}, z_{\mathrm{b}}=2 \mathrm{~cm}\right.$, $\alpha_{0}=50 \mathrm{yr}^{-1}, x_{\mathrm{irr}}=1 \mathrm{~cm}$ ) cause minimal modulation of $\Delta^{13} \mathrm{C}_{\text {primary-bulk. The influence of modern benthic fauna }}$ $\left(D_{\mathrm{b} 0}>5 \mathrm{~cm}^{2} \mathrm{yr}^{-1}, \quad z_{\mathrm{b}}=3 \mathrm{~cm}, \alpha_{0}>50 \mathrm{yr}^{-1}, x_{\mathrm{irr}}=2 \mathrm{~cm}\right)$ would suppress $\delta^{13} \mathrm{C}$ modifications caused by OC-steered diagenetic carbonate alteration and authigenic carbonate addition. On the other hand, the absence of benthic fauna (postextinction situation) allows for an unconstrained impact of the previously cited OC-controlled trajectories of $\mathrm{C}$ isotope modification during bulk-rock formation and stabilization under $\mathrm{P}-\mathrm{Tr}$ environmental conditions.

\section{Simulation of a virtual carbon isotope time series}

In order to understand the obtained temporal patterns in residual $\delta^{13} \mathrm{C}_{\text {carb }}$ variability, a series of reactive transport 
(a) Low OC

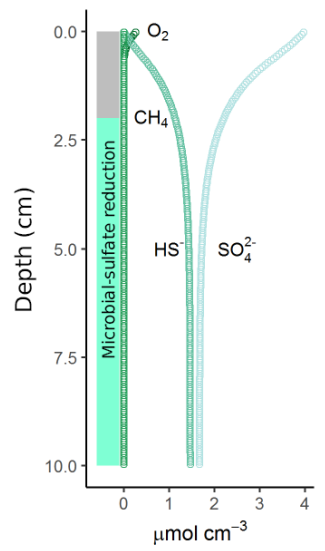

(b) Low OC

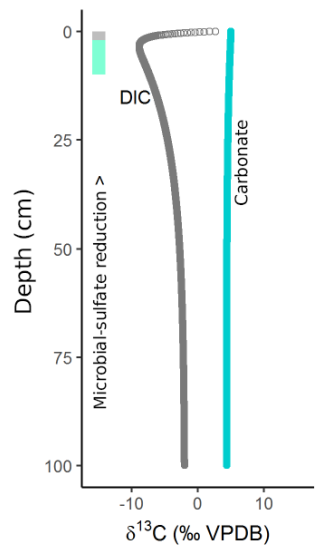

(c) High OC

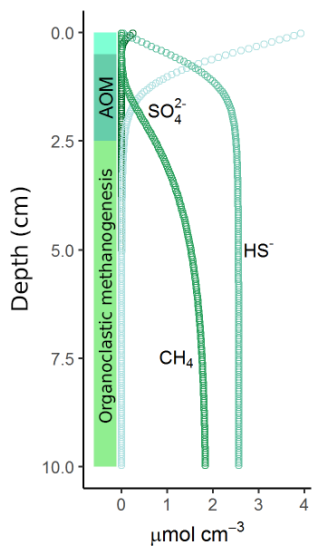

(d) High OC

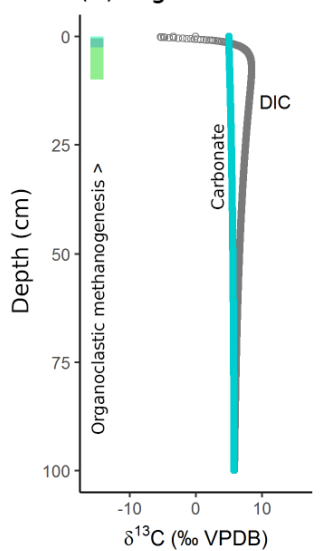

(e) Pre-extinction

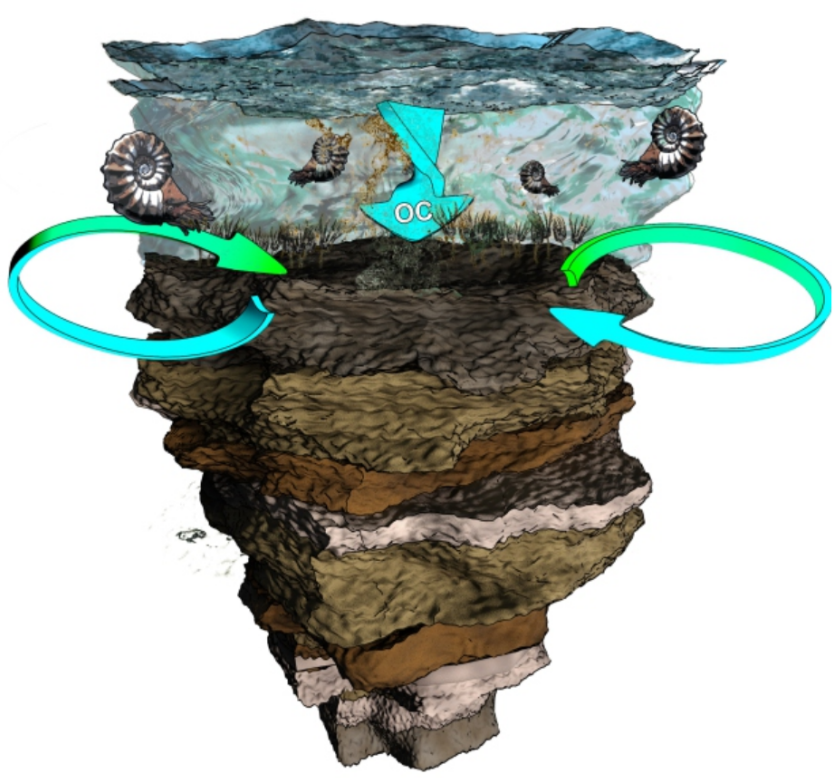

(f) Post-extinction

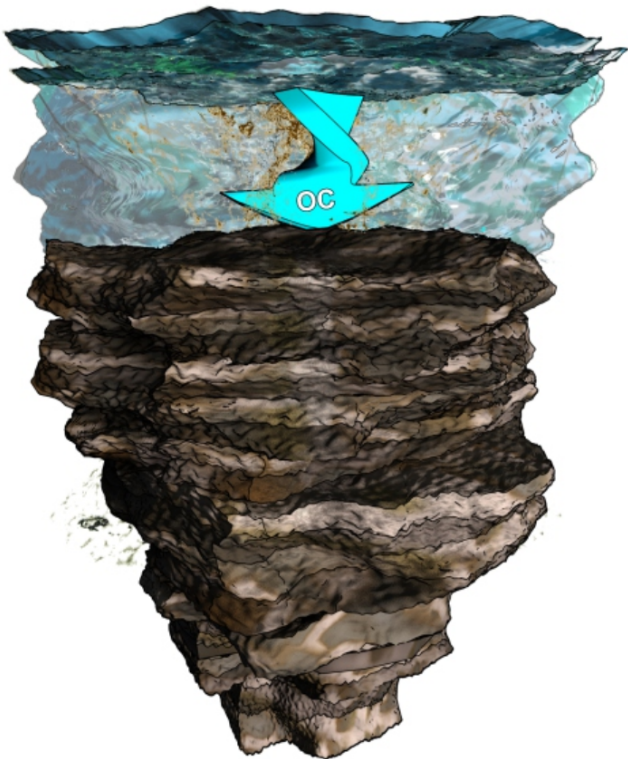

Figure 4. Diagenetic depth profiles of Late Permian sea-floor sediments of (a) oxidized and reduced solutes under a low shelf OC flux $500 \mu \mathrm{mol} \mathrm{cm} \mathrm{cm}^{-3} \mathrm{yr}^{-1}$, (b) DIC and carbonate $\delta^{13} \mathrm{C}$ forced with a low shelf OC flux $500 \mu \mathrm{molcm} \mathrm{cm}^{-3} \mathrm{yr}^{-1}$, (c) oxidized and reduced solutes under a high OC flux $1200 \mu \mathrm{mol} \mathrm{cm} \mathrm{cm}^{-3} \mathrm{yr}^{-1}$, (d) DIC and carbonate $\delta^{13} \mathrm{C}$ forced with a high OC flux $7000 \mu \mathrm{mol} \mathrm{cm}^{-3} \mathrm{yr}^{-1}$. (e) Situational sketch of pre-extinction bulk-carbonate accumulation with a normal OC flux and active benthic fauna and (f) situational sketch of the postextinction sedimentation with elevated OC accumulation, removal of metazoan benthic fauna and consequentially reduced sediment mixing (artwork by Mark Schobben; http://cyarco.com).

models have been solved to steady state under varying OC sedimentation regimes. The virtual time series approach is an amalgamation of multiple sets of individual reactive transport model runs (50 model iterations $=1$ set $=1$ time unit) sliding across a timeline of length 100 and with time increments of length one (Fig. 7).

By performing sensitivity tests (Sect. 3.2.3), we have established that there is a systematic relation between OC arriving at the seabed and the magnitude of bulk-rock $\mathrm{C}$ isotope alteration, which is expressed as $\Delta^{13} C_{\text {primary-bulk }}$ (Fig. 5). Hence, the initial $F_{\text {OC }}$ can be estimated because the
$\Delta^{13} C_{\text {primary-bulk }}$ can be approximated by the $\mathrm{C}$ isotope offset between calcite from well-preserved Permian brachiopods and time-equivalent bulk-rock samples $(\sim 1.0 \%$ ) (Schobben et al., 2016) and equates to $802 \mu \mathrm{molcm} \mathrm{cm}^{-3} \mathrm{yr}^{-1}$. The $F_{\mathrm{OC}}$ is subsequently modulated for each set (i.e., time unit) based on the observation that $\mathrm{OC}$ accumulation increases by a factor of 4 across the P-Tr transition (Algeo et al., 2013) and by linearly scaling this parameter to the observed residual $\delta^{13} \mathrm{C}_{\text {carb }}$ variability (IQR) as obtained from Fig. 2, yielding a continuous range for $F_{\mathrm{OC}}\left(802 \leq F_{\mathrm{OC}} \leq 3206 \mu \mathrm{mol} \mathrm{cm}^{-3} \mathrm{yr}^{-1}\right)$. 
(a)

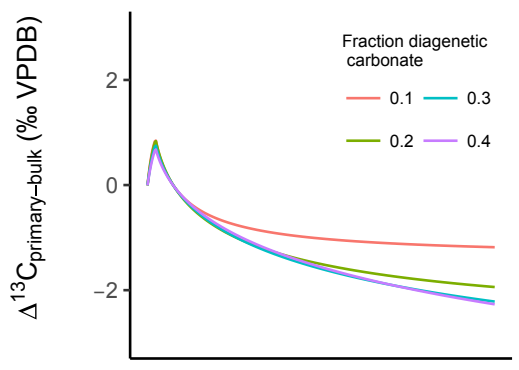

(c)

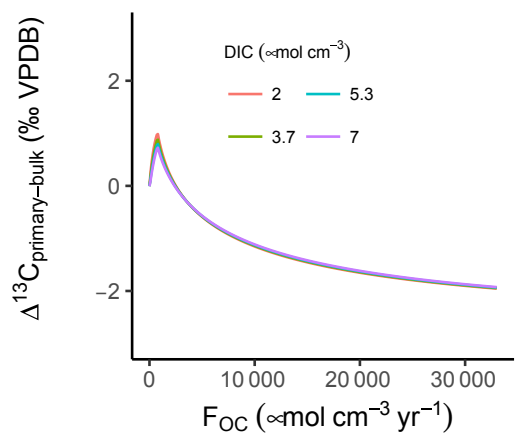

(e)

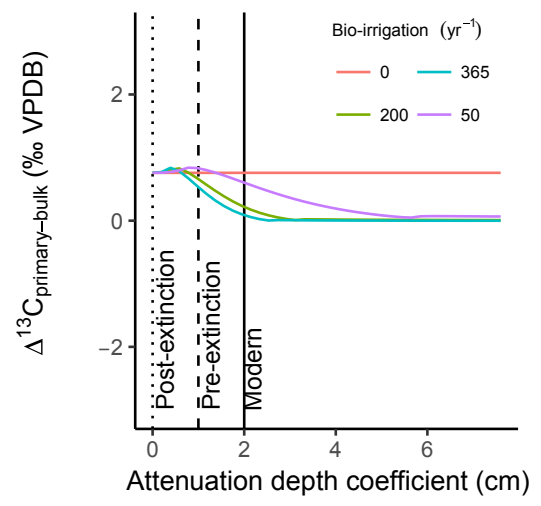

(b)

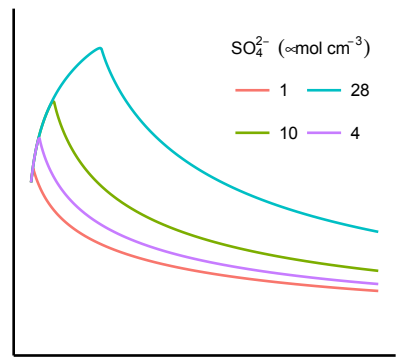

(d)

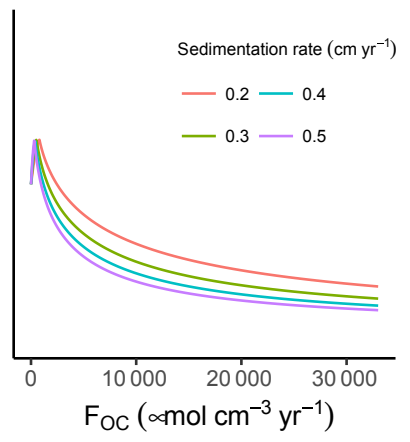

(f)

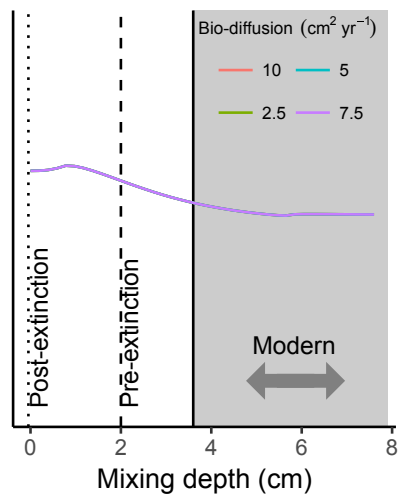

Figure 5. Sensitivity experiment for diagenetic carbonate alteration through equilibrium recrystallization with depth designed to investigate the forcing effect of (a) the fraction of diagenetic carbonate incorporated ( $\left.f_{\text {dia }}\right)$, (b) sulfate content of overlying water, (c) DIC content of overlying water and (d) sedimentation rate ( $v$ and $w$ ) on the carbon isotope offset between the diagenetic end-member rock and the primary calcite over a range of $F_{\mathrm{OC}}$. Panels (e) and (f) depict sensitivity experiments for bio-irrigation $\left(\alpha_{0}\right)$ and bio-diffusion $\left(D_{\mathrm{b} 0}\right)$, respectively, on diagenetic altered carbonate for changing modes of sediment reworking and irrigation by biota under a normal OC flux $\left.(730 \mu \mathrm{mol} \mathrm{cm})^{-3} \mathrm{yr}^{-1}\right)$. An increasingly suppressed alteration of the end-member carbon isotope signal is observed for the pre-extinction (Dale et al., 2016) and modern (van de Velde and Meysman, 2016) depth profiles compared with sediment that is not inhabited by metazoans (post-extinction).

With regard to examining the effects of spatially distinct OC sinking fluxes and/or benthic fauna on the lateral distribution of OC, we forced individual model runs (within one time unit) with slightly deviating $F_{\mathrm{OC}}$ values. The maximum attained $F_{\mathrm{OC}}$ variability is constrained by adopting a lognormal skewed density distribution (R package emdbook; Bolker, 2008, 2016) around the former established $F_{\mathrm{OC}}$, which represents the population's median value (Fig. 7), and by randomly selecting a value from the created distribution. A log-normal skewed density distribution has been chosen to represent natural variation in the $F_{\mathrm{OC}}$-population, which would be signified by variation that is skewed towards heavy sea-floor OC loading in rare instances, whereas most variation is smaller in magnitude and can modulate the flux towards both smaller and higher contributions. Temporal variations in this parameter are attained by modulating the width of the sample population ranging up to a factor of 1.5. This lateral OC dispersion parameter is also linearly scaled to the observed residual $\delta^{13} \mathrm{C}_{\text {carb }}$ variability (IQR) as obtained from Fig. 2. This results in sample population variations 
(a)

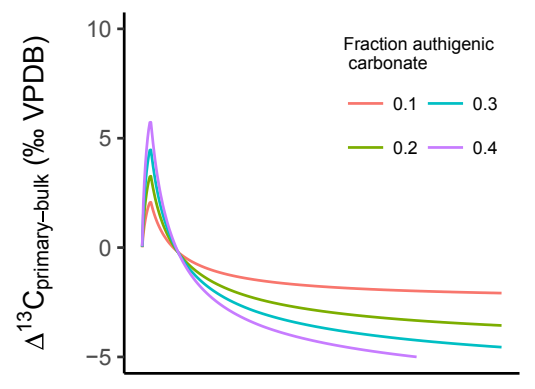

(c)

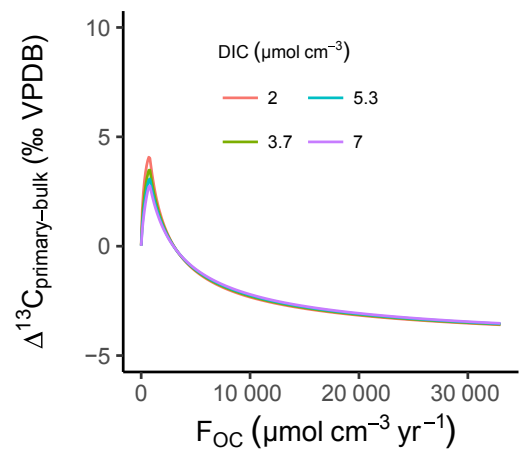

(e)

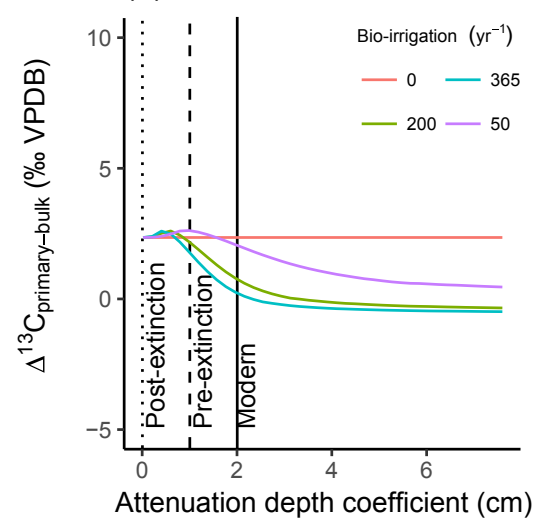

(b)

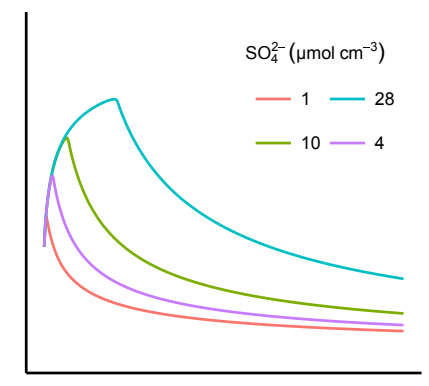

(d)

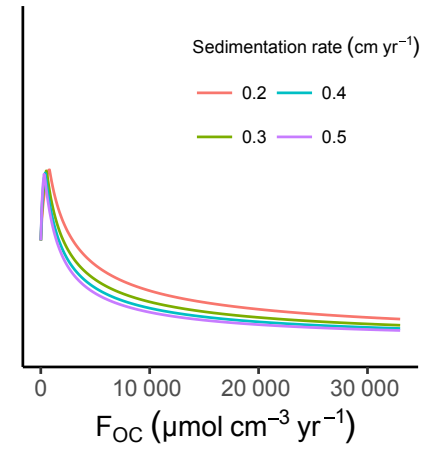

(f)

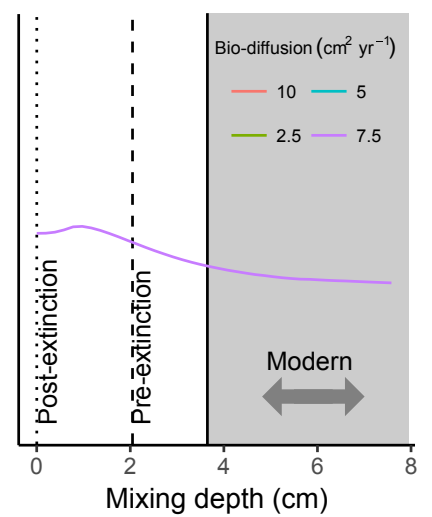

Figure 6. Sensitivity experiment for authigenic carbonate addition through sea-floor cementation designed to investigate the forcing effect of (a) the fraction of authigenic carbonate $\left(f_{\text {auth }}\right)$ incorporated, (b) sulfate content of overlying water, (c) DIC content of overlying water and (d) sedimentation rate $(v$ and $w)$ on the carbon isotope offset between the diagenetic end-member rock and the primary calcite over a range of $F_{\mathrm{OC}}$. Panels (e) and (f) depict sensitivity experiments for bio-irrigation $\left(\alpha_{0}\right)$ and bio-diffusion $\left(D_{\mathrm{b} 0}\right)$, respectively, on authigenic carbonate addition for changing modes of sediment reworking and irrigation by biota under a normal OC flux $\left(730 \mu \mathrm{mol} \mathrm{cm}^{-3} \mathrm{yr}^{-1}\right)$. An increasingly suppressed alteration of the end-member carbon isotope signal is observed for the pre-extinction (Dale et al., 2016) and modern (van de Velde and Meysman, 2016) depth profiles compared with sediment that is not inhabited by metazoans (post-extinction).

of $524 \leq$ median absolute deviation $\leq 3889 \mu \mathrm{mol} \mathrm{cm}{ }^{-3} \mathrm{yr}^{-1}$ when combined with the initial $F_{\mathrm{OC}}$ range for homogeneously and more heterogeneously dispersed sedimentary OC, respectively.

The initial carbon isotope composition of $F_{\text {carb }}$ is based on the median $\delta^{13} \mathrm{C}_{\text {carb }}$ values of the first time unit of the pooled Iranian dataset (Fig. 1). This value is subsequently corrected by $-1.0 \%$ based on the systematic isotope offset between bulk carbonate and pristine carbonate from brachiopod shells (Schobben et al., 2016) in order to obtain the $\mathrm{C}$ isotope value of $F_{\text {carb }}$. The systematic relationship of OC sedimentation

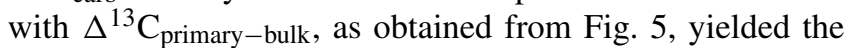
primary $\delta^{13} \mathrm{C}$ of calcium carbonate particles arriving at the seabed for successive time units.

The processes governing increased authigenic sea-floor cementation in post-extinction strata are largely speculative. 


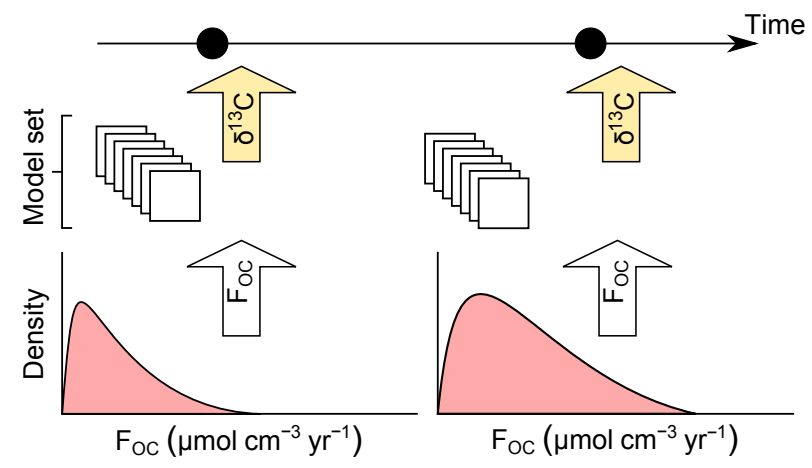

Figure 7. Schematic depiction of the work flow behind the virtual carbon isotope time series. Model sets consist of 50 separate reactive transport model solutions driven by a randomly selected $F_{\text {OC }}$. The randomly generated organic OC flux values translate into a density distribution with a right-skewed tail. Increased $F_{\mathrm{OC}}$ and a widening of the value range is used to simulate increased spatial OC heterogeneity.

However, undisturbed substrates are a feature required to enable the growth of calcifying microbial mats, regardless of the mechanism inducing the global-scale proliferation of these sea-floor precipitates (e.g., Garcia-Pichel et al., 2004). Considering this universal control, it is justified to assume a direct link between bioturbation intensity and authigenic seafloor cementation. This assumption links both forms of carbonate rock formation and stabilization: equilibrium recrystallization and authigenic sea-floor cementation. The probability $(p)$ of producing authigenic sea-floor cements has been assumed to vary linearly in the range $0.01 \leq p \leq 0.1$ following the upper two terciles of the range attained by the previously defined OC dispersion parameter. This definition determines the response of introducing authigenic sea-floor cement $\delta^{13} \mathrm{C}$ to the sample pool.

In order to further simulate the mass extinction of marine metazoans across the end-Permian extinction on sedimentary conditions, the parameters that define bio-mixing and bioirrigation (Sect. 3.2.2) are set to zero from time unit 60 onward (equivalent to biozone G; Fig. 1 and Table 1). In addition, it has been postulated that sedimentation rates increased over the P-Tr transition (Algeo and Twitchett, 2010), so the sedimentation rate (of $v$ and $w$ ) was modulated at time unit 70 (equivalent to biozone H; Fig. 1 and Table 1). However, a conservative 2-times sedimentation increase is adopted, as the previously cited estimates largely hinge on calculations based on the duration of the respective stages, which are subject to continuous modification ( $\mathrm{Li}$ et al., 2016). The $f_{\text {dia }}$ and/or $f_{\text {auth }}$ for both trajectories of carbonate rock stabilization is kept constant at 0.2. The final bulk-rock carbon isotope value is obtained by using the mass balance from the calculated primary and diagenetic and/or authigenic carbonate components.

A total of 5050 reactive transport models have been solved in order to match the length and resolution of the cumulative

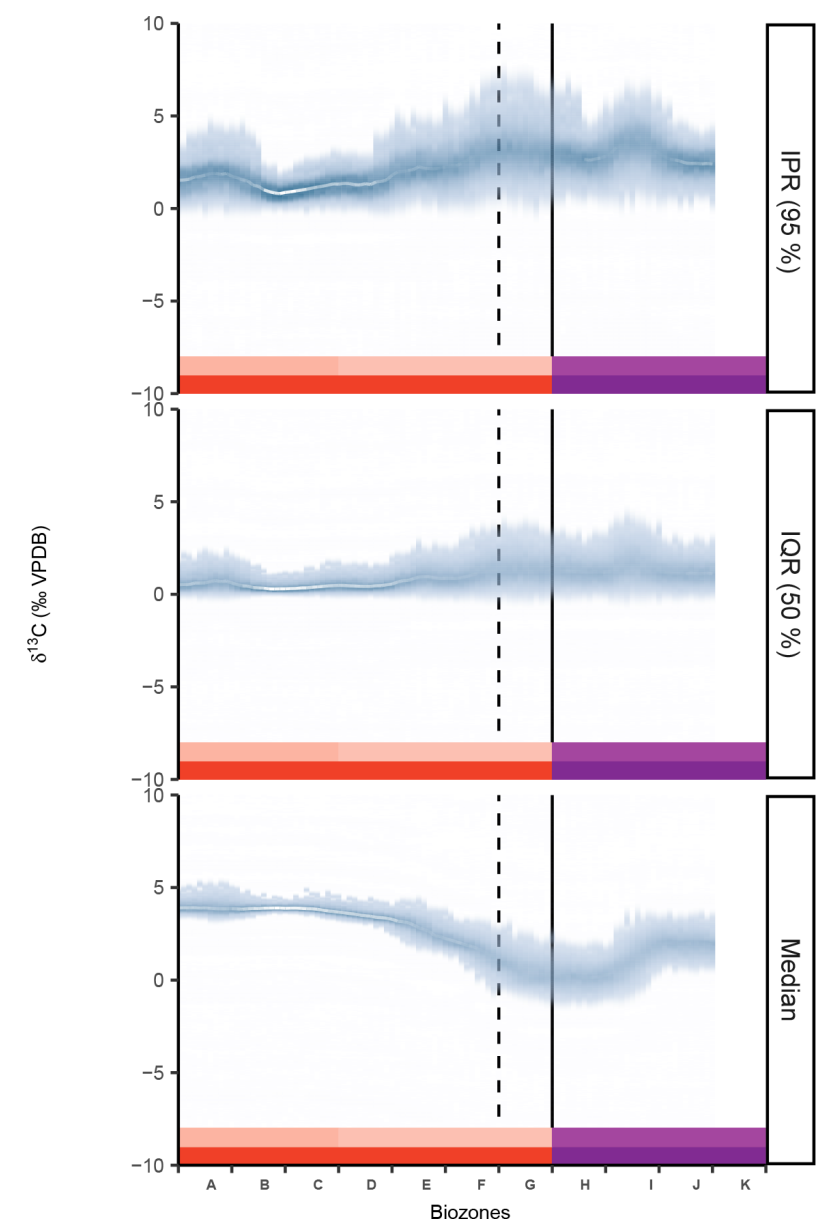

Figure 8. Subsampled virtual carbon isotope time series with model results plotted as "visually weighted" trends. Each time unit incorporates 50 model iterations with a randomly chosen OC flux from a log-normal skewed density distribution. The time series simulates an increase of 4 times the average OC flux, a 1.5 times increase in the spatial heterogeneity of OC accumulation and increased likelihood of producing sea-floor authigenic carbonate to a maximum of 1 in 10. Bioturbation (expressed as bio-mixing and bio-irrigation) is modulated at the extinction horizon to mimic the effect of a dieoff among benthic organisms. In addition, sedimentation ( $v$ and $w$ ) is increased twofold over the $\mathrm{P}-\mathrm{Tr}$ transition (see main text for sources).

"real" $\delta^{13} \mathrm{C}$ time sequence from sites in Iran (Fig. 1). The resulting virtual time series of model runs forced by previously established value ranges for the OC sinking flux, sediment homogeneity and authigenic mineral addition is depicted in Fig. 8. Although these steady-state solutions will not always be truly representative of a dynamic sedimentary environment (e.g., sedimentation rate changes and sediment reworking), we conclude that the conceptualized model (Sect. 2) and selected parameter values can explain trends in residual carbon isotope variability. 


\section{Discussion}

\subsection{Stochastic carbon isotope signatures of the Permian-Triassic boundary beds}

Global comparisons of $\mathrm{P}-\mathrm{Tr}$ carbon isotope records have uncovered disparate $\delta^{13} \mathrm{C}$ trends and excursions (Fig. 1). These deviations are often encountered on refined stratigraphic and lateral scales, complicating interregional high-resolution correlations (Heydari et al., 2001; Hermann et al., 2010). Subaerial exposure and projected trajectories of bulk-carbonate stabilization under the influence of meteoric fluids and high water-rock ratios might be invoked to explain this disparity (Heydari et al., 2001; Li and Jones, 2017). Other studies have pointed to stratigraphic variations in predominant mineral rock composition as a source of $\delta^{13} \mathrm{C}_{\text {carb }}$ modulations, citing the mineral-specific isotope offset between aragonite, dolomite and low-Mg calcite (Brand et al., 2012b; Heydari et al., 2013; Schobben et al., 2016; Li and Jones, 2017).

In this study, we provide an alternative explanation for disparate second-order $\delta^{13} \mathrm{C}_{\text {carb }}$ excursions involving the observed stochastic residual $\delta^{13} \mathrm{C}$ variability on a refined spatial scale (Fig. 1). We regard this test to be of importance, as a transgression marks the boundary beds and Lower Triassic deposits (Fig. 1). Furthermore, subaerial exposure and consequential early rock stabilization with the high waterto-rock ratios (open system) of the studied localities is unlikely to have left an isotopic overprint. Under such circumstances, regionally extensive carbonate sediment dissolution through contact with an undersaturated solution could have sourced the underlying sediment pile with saturated fluids for cementing (Bathurst, 1975). However, evidence of such exposure in the form of karstification is absent in the studied locations (Leda et al., 2014; Yin et al., 2014). A recent study on the Meishan section suggests that recrystallization (i.e., zoned dolomite crystals) and the modification of the $\mathrm{C}$ isotope composition of certain stratigraphic levels was forced by a short-lived regression and consequential exposure to meteoric water ( $\mathrm{Li}$ and Jones, 2017). However, the assignment of such petrological indices to specific diagenetic environments is often fraught with uncertainties, and it is not uncommon for alleged diagnostic features to occur in a range of diagenetic environments (Melim et al., 2002). Although a complete exclusion of isotope resetting by meteoric water is not possible, it is possible that a large portion of the global carbonate archive lithified without being subjected to meteoric fluids, therefore justifying the exploration of alternative modes of isotope resetting.

Systematically ${ }^{12} \mathrm{C}$-depleted bulk rock relative to brachiopod calcite (Schobben et al., 2016) further counters the notion of a variable predominance of an aragonite precursor for Permian carbonate rock (Brand et al., 2012b; Heydari et al., 2013). Nonetheless, secondary calcite and dolomite additions might be a causal factor behind observed $\delta^{13} \mathrm{C}$ variability. However, these additions can also be the result of in situ microbially steered mineral formation, which incorporates metabolically produced DIC isotope signatures (Bontognali et al., 2014; Li and Jones, 2017). As such, our conceptualized model is not mutually exclusive with regards to carbonate polymorph compositional changes, but it does not require rapid global secular marine ion inventory changes. Moreover, our model outcome predicts $\delta^{13} \mathrm{C}$ variation driven solely by small biologically steered mineral contributions ( $f_{\text {dia }}$ and/or $f_{\text {auth }}=0.2$; Fig. 6), whereas the recorded $\delta^{13} \mathrm{C}$ fluctuations are up to 10 times higher in amplitude than otherwise predicted for thermodynamically driven mineralspecific isotope compositional offsets (Brand et al., 2012b; Heydari et al., 2013). Note also that the mineral-specific isotope offset would require bulk-rock samples to display effectively complete (100\%) mineral compositional changes to a pure carbonate polymorph composition. In contrast, our model predicts a mechanism that can introduce temporal variation in spatially heterogeneous carbonate polymorph assemblies and associated isotope compositional differences through post-depositional processes driven by spatially and temporally variable $\mathrm{OC}$ accumulation comparable to modern ranges (Müller and Suess, 1979). Depleted marine dissolved sulfate concentrations would have exacerbated the sensitivity of carbonate rock towards only small deviations in this allochthonous $\mathrm{C}$ source (Figs. 5 and 6). Combined with a less well-mixed sediment and microbially steered cementation, this model can account for the entirety of the observed residual $\delta^{13} \mathrm{C}_{\text {carb variability. }}$

\subsection{The carbon isotopic composition of the Permian-Triassic DIC reservoir}

The first-order P-Tr negative carbon isotope trend can be explained by changes in the sources and sinks of the long-term ( $>100 \mathrm{ky}$ ) carbon cycle, e.g., a reorganization of organic carbon burial and volcanic $\mathrm{CO}_{2}$ outgassing (Renne et al., 1995; Kump and Arthur, 1999; Berner, 2002). Carbon-cycle partitioning between the deep and shallow ocean through the marine biological pump have been proposed to explain the depth-gradient isotope differences (Meyer et al., 2011; Song et al., 2013) or a rapid ( $<100 \mathrm{ky}) \mathrm{C}$ isotope excursion (Rampino and Caldeira, 2005). On the one hand, the stochastic residual $\delta^{13} \mathrm{C}_{\text {carb }}$ variability on a confined centimetremetre stratigraphic scale is inherently difficult to reconcile with transient perturbations in the dynamic $\mathrm{C}$-cycle equilibrium enforced by repeated biological reordering of DIC between the shallow and deep ocean (i.e., consecutive events of global productivity increase and wholesale collapse). On the other hand, if lateral variations in marine DIC-C isotope composition account for $\delta^{13} \mathrm{C}_{\text {carb }}$ variability, water column mixing would likely erase spatial compositional differences on smaller scales ( $<\mathrm{km}$ scale). For example, residual $\delta^{13} \mathrm{C}_{\text {carb }}$ variability recorded at Meishan (Fig. 1) on a centimetre to metre scale cannot be reconciled with the heterogeneity of the overlying water mass, and less well-mixed sed- 
iments become a more acceptable alternative. Although the geographically disparate $\mathrm{C}$ isotope signals of different sites in Iran ( $>\mathrm{km}$ scale) could instead be accounted for by the heterogeneity of water masses, the temporal trend in the amplitude of the residual $\delta^{13} \mathrm{C}_{\text {carb }}$ variability is similar for both China and Iran (Fig. 2). An overarching control of the hereinvoked OC-steered diagenetic mechanism is the most parsimonious model to explain this geographical coherence.

Sea-floor methane clathrate dissociation, coal and organicrich sediment combustion through igneous intrusions and ocean $\mathrm{Ni}$ fertilization stimulating methane production by methanogens are viable sources of transient $(<100 \mathrm{ky})$ isotope-depleted carbon contributions to the atmosphereocean system (Erwin, 1993; Knoll et al., 1996; Krull and Retallack, 2000; Retallack and Jahren, 2008; Svensen et al., 2009; Rothman et al., 2014). Although all of the cited mechanisms are conceivable triggers for defined second-order $\delta^{13} \mathrm{C}_{\text {carb }}$ excursions, they are less likely to create spatially divergent isotope trends and repeated temporally distinct fluctuations; instead, they essentially reflect bed-to-bed variation. The existence of transient carbon isotope excursions is also unlikely considering the predicted elevated DIC levels of an ocean without pelagic calcifiers, resulting in conservative behaviour of the DIC pool towards transient $\mathrm{C}$ isotope perturbations (i.e., increasing the system response time; Kump and Arthur, 1999; Zeebe and Westbroek, 2003; Rampino and Caldeira, 2005). Nonetheless, second-order (transient and depth-gradient) $\mathrm{C}$ isotope signals of a primary origin might still be imprinted in the isotope records. However, rock formed under the previously outlined marine depositional conditions (with intensified spatially heterogeneous trajectories of $\mathrm{C}$ isotope alteration) increases the chance of sampling spatially variable and diagenetically modulated $\delta^{13} \mathrm{C}$ signals, and these would obscure primary signals.

\subsection{Perspectives on the Permian-Triassic carbonate archive: stratigraphy, biological evolution and the global biogeochemical carbon cycle}

These findings put renewed constraints on the application of whole-rock $\delta^{13} \mathrm{C}$ as a high-resolution stratigraphic tool. Diagenesis forced by a recrystallization process under the influence of meteoric fluids, high fluid-to-rock ratios and oxidized terrestrially derived organics is generally considered to be the main driver of bulk-rock $\mathrm{C}$ isotope alteration (Brand and Veizer, 1981; Marshall, 1992; Brand et al., 2012a, b). Rocks without petrological evidence of meteoric fluids percolating through voids and interacting with sediment grains, e.g., palaeokarsts, blocky calcite and pendant cements, are usually regarded as pristine and minimally isotopically altered (Veizer et al., 1999; Flügel, 2010; Brand et al., 2012a, b). Regarding the observed P-Tr residual whole-rock $\delta^{13} \mathrm{C}$ variability and model predictions, we have shown that under certain marine and sedimentary situations marine carbonate rock diagenesis can introduce significant $\delta^{13} \mathrm{C}$ fluctuations to the whole-rock isotope composition. The insight gained here undermines the idea of using second-order $\delta^{13} \mathrm{C}$ fluctuations as stratigraphic markers, which are often confined to limited stratigraphic intervals (e.g., individual limestone beds) without a proper understanding of the potential effects of diagenetic carbon isotope modification. At least for the data presented here, we can demonstrate that shifts in bulk-rock $\delta^{13} \mathrm{C}$ smaller than classical biozonation schemes have to be considered with caution when they coincide with the sedimentological features of reduced bioturbation (e.g., lamination) and likely do not serve as a globally universal marker. Instead, long-term first-order trends cross-cutting formational boundaries (see Supplement) have a higher likelihood of representing secular variation in seawater DIC isotope composition and are largely unaffected by marine diagenetic processes (Fig. 1). Extrapolation of our model results to Mesozoic and Cenozoic bulk-carbonate records signified by comparatively reduced $\delta^{13} \mathrm{C}$ variability might reflect buffering of highly variable diagenetic $\mathrm{C}$ isotope contributions under elevated marine sulfate levels and physical sediment mixing by benthic fauna.

The carbonate chemical signal towards increased $\delta^{13} \mathrm{C}$ variability supports the global significance of three parameters during the deposition of $\mathrm{P}-\mathrm{Tr}$ carbonate rock: reduced sediment mixing, authigenic precipitates and heterogeneous OC accumulation. Although we have postulated a connection between sediment lamination and $\mathrm{C}$ isotope variability, the relation of these observations to the end-Permian mass extinction is unconstrained. The cataclysmic mechanism that drove the extinction of benthic fauna is still a matter of debate, but bottom water anoxia is one of the main contenders. This could have been caused by decreased seawater oxygenation instigated by stagnating ocean circulation (Wignall and Twitchett, 1996; Winguth et al., 2015). Alternatively, a higher OC sinking flux might have led to increased $\mathrm{O}_{2}$ drawdown through aerobic respiration and $\mathrm{H}_{2} \mathrm{~S}$ production by sulfate-reducing microbes, leading to widespread marine euxinia (Meyer et al., 2008; Algeo et al., 2013; Schobben et al., 2015). However, $\delta^{13} \mathrm{C}$ variability complies most compellingly with at least continuing OC accumulation over the studied interval and thereby largely undermines scenarios of reduced primary productivity (e.g., Rampino and Caldeira, 2005). On the other hand, the proliferation of post-extinction authigenic sea-floor precipitates (e.g., thrombolites, stromatolites and fan-shaped structures) likely represents a symptom of reduced sediment disturbance and elevated carbonate saturation (Kershaw et al., 2009). Since some of the more conspicuous post-extinction sea-floor structures have been connected with microbial communities and distinct metabolism-mediated isotope signatures (e.g., Heindel et al., 2013), they might be equally important constituents of the observed spatial $\delta^{13} \mathrm{C}$ variability. Geographic differences observed as systematically higher residual $\delta^{13} \mathrm{C}$ variability at the Chinese localities are suggestive of a regionally distinct hydrographic and depositional setting. This regional feature 
could be linked with evidence of episodic Late Permian euxinic conditions in the South China basin (Grice et al., 2005; Cao et al., 2009). Comparatively higher and more spatially variable OC loading of the sea floor in the South China basin under these circumstances might be triggered by enhanced primary productivity or OC sinking fluxes (Algeo et al., 2011, 2013). On the other hand, the depositional sites found in Iran lack evidence for bottom water anoxia and favour other drivers behind the marine faunal extinction, e.g., thermal stress or ocean acidification (Leda et al., 2014; Schobben et al., 2014; Clarkson et al., 2015).

In addition to capturing regional biological expressions of the global faunal disruption, our approach illuminates potentially important feedbacks of the Earth system that control the global-scale carbon cycle. Recently, attention has increased on the potential significance of authigenic carbonate production for the global carbonate reservoir (Schrag et al., 2013) and the addition of authigenic carbonate to Permian and Triassic carbonate-bearing sequences (Schobben et al., 2016; Zhao et al., 2016). The numerical exercise highlights the link between local sedimentary OC-cycling and bulkrock diagenetic stabilization, hinting at the potentially significant portion of remineralized $\mathrm{OC}$ sequestered by authigenic carbonates. Additionally, bulk-rock residual $\delta^{13} \mathrm{C}$ variability might serve as an indicator of infaunal biological activity, effectively preserving an ecological signal, which could in turn be an indicator of local sedimentary C-cycling. This sub-cycle is strongly controlled by bioturbation and controls the amount of buried organic matter and the supply of electron acceptors (Canfield, 1989; Canfield et al., 1993). These fluxes drive carbon removal from the exogenic carbon reservoir and potentially require a revision of generally accepted constraints on these budgets, including during events with postulated major $\mathrm{C}$-cycle perturbations, such as the latest Permian extinction.

\section{Conclusions}

The $\delta^{13} \mathrm{C}_{\text {carb }}$ record straddling the P-Tr boundary of Iran and South China can be decomposed in a first-order temporal trend with a negative trend marking the transition beds and superimposed second-order residual $\delta^{13} \mathrm{C}$ variability. The primary goal of the current study was to delineate the nature of the second-order $\delta^{13} \mathrm{C}$ fluctuations, which harbour a reproducible temporal pattern towards increased variability across the extinction beds. By investigating the origin of these second-order geochemical signals, it is possible to better constrain the limits of carbon isotope chemostratigraphy, most notably the time resolution on which it can be applied. Having established that second-order $\mathrm{C}$ isotope variability traces local effects rather than the global carbon reservoir, we discerned that mineralogical heterogeneity and meteorically steered cementation are unsatisfactory candidates to explain this spread in $\delta^{13} \mathrm{C}$. Hence, the possibility of metabolism- steered carbonate addition is more likely, as the anaerobic microbial pathway introduces isotopically depleted (or enriched) carbon to the porewater and the same microbes are often connected with the production of diagenetic and authigenic carbonates. Moreover, organic carbon degradation occurs in a part of the sediment column signified by high reactivity of the primary carbonate sediments. By testing these assumptions with reactive transport models and with the construction of a virtual time series, we can recreate the observed variability in the end-member bulk-rock $\delta^{13} \mathrm{C}$ composition by inducing the heterogeneous spatial distribution of sedimentary OC, i.e., a reduction of physical sediment mixing or spatially divergent OC sinking fluxes. Authigenic sea-floor cementation, possibly mediated by microbial mat communities, is another source that might have introduced diagenetic overprints in the P-Tr boundary beds. On the other hand, these mechanisms can still preserve long-term trends in oceanic DIC carbon isotope composition. These findings strengthen the notion that bulk carbonate $\delta^{13} \mathrm{C}$ is a fruitful source of information that records secular trends in carbon cycle evolution and potentially informs us about the biosphere, notably infaunal animal activity, sea-floor microbial communities and $\mathrm{OC}$ delivery to the sea floor.

Code and data availability. Data visualization, statistical data treatment and the reactive transport model have been written in the $\mathrm{R}$ language. The $\mathrm{R}$ scripts and the datamined and newly produced ${ }^{13} \mathrm{C}$ values are available on the GitHub repository: https://github.com/MartinSchobben/carbonate (https://doi.org/10.5281/zenodo.888754).

\section{The Supplement related to this article is available online at https://doi.org/10.5194/cp-13-1635-2017-supplement.}

Author contributions. MS designed the study. MS, CK, VH, AG and LL collected material in the field and prepared samples for isotope analysis. US, CK and CVU performed C isotope analysis. MS and SvdV constructed the numerical model. MS and JG data mined the complementary published $\mathrm{C}$ isotope results. All authors provided intellectual input and contributed to writing the paper.

Competing interests. The authors declare that they have no conflict of interest.

Acknowledgements. We thank Sylvain Richoz (Lund University, Sweden) and Yoshitaka Kakuwa (University of Tokyo, Japan) for providing us with published carbon isotope data. We acknowledge support provided by the Aras Free Zone Office and Adel Najafzadeh (Tabriz, Iran) to sample the Ali Bashi, Aras Valley and Zal sites and Bo Petersen (University of Copenhagen, 
Denmark) for analytical assistance in the laboratory. This project was funded by the Deutsche Forschungsgemeinschaft (DFG; projects KO1829/12-1, KO1829/12-2, KO2011/8-1, KO1829/18-1 and FOR 2332). Martin Schobben is currently funded by a DFG Research Fellowship (SCHO 1689/1-1), Sebastiaan van de Velde is supported by a PhD fellowship from the Research Foundation Flanders (FWO), Clemens Vinzenz Ullmann acknowledges funding from NERC grant NE/N018508/1 and Simon W. Poulton acknowledges support from a Royal Society Wolfson Research Merit Award. The publication of this paper was funded by the Open Access Fund of the Leibniz Association.

Edited by: Arne Winguth

Reviewed by: two anonymous referees

\section{References}

Algeo, T. J. and Twitchett, R. J.: Anomalous Early Triassic sediment fluxes due to elevated weathering rates and their biological consequences, Geology, 38, 1023-1026, https://doi.org/10.1130/G31203.1, 2010.

Algeo, T. J., Kuwahara, K., Sano, H., Bates, S., Lyons, T., Elswick, E., Hinnov, L., Ellwood, B., Moser, J., and Maynard, J. B.: Spatial variation in sediment fluxes, redox conditions, and productivity in the Permian-Triassic Panthalassic Ocean, Palaeogeogr. Palaeoclimatol. Palaeoecol., 308, 65-83, https://doi.org/10.1016/j.palaeo.2010.07.007, 2011.

Algeo, T. J., Henderson, C. M., Tong, J., Feng, Q., Yin, H., and Tyson, R. V.: Plankton and productivity during the Permian-Triassic boundary crisis: An analysis of organic carbon fluxes, Global Planet. Change, 105, 52-67, https://doi.org/10.1016/j.gloplacha.2012.02.008, 2013.

Alroy, J., Aberhan, M., Bottjer, D. J., Foote, M., Fürsich, F. T., Harries, P. J., Hendy, A. J. W., Holland, S. M., Ivany, L. C., Kiessling, W., Kosnik, M. A., Marshall, C. R., McGowan, A. J., Miller, A. I., Olszewski, T. D., Patzkowsky, M. E., Peters, S. E., Villier, L., Wagner, P. J., Bonuso, N., Borkow, P. S., Brenneis, B., Clapham, M. E., Fall, L. M., Ferguson, C. A., Hanson, V. L., Krug, A. Z., Layou, K. M., Leckey, E. H., Nürnberg, S., Powers, C. M., Sessa, J. A., Simpson, C., Tomašových, A., and Visaggi, C. C.: Phanerozoic trends in the global diversity of marine invertebrates, Science, 321, 97-100, https://doi.org/10.1126/science.1156963, 2008.

Arp, G., Reimer, A., and Reitner, J.: Photosynthesisinduced biofilm calcification and calcium concentrations in Phanerozoic oceans, Science, 292, 1701-1704, https://doi.org/10.1126/science.1057204, 2001.

Auguie, B.: gridExtra: Miscellaneous Functions for "Grid" Graphics, available at: http://CRAN.R-project.org/package=gridExtra (last access: November 2017), r package version 2.0.0, 2016.

Banner, J. L. and Hanson, G. N.: Calculation of simultaneous isotopic and trace element variations during water-rock interaction with applications to carbonate diagenesis, Geochim. Cosmochim. Ac., 54, 3123-3137, https://doi.org/10.1016/00167037(90)90128-8, 1990.

Bathurst, R. G. C.: Cementation, in: Developments in sedimentology 12: Carbonate sediments annd their diagenesis, 10, 415457, Elsevier, https://doi.org/10.1016/S0070-4571(08)70904-X, 1975.
Bathurst, R. G. C.: Microfabrics in Carbonate Diagenesis: A Critical Look at Forty Years in Research, Springer New York, New York, https://doi.org/10.1007/978-1-4684-9421-1_1, 1993.

Baud, A., Magaritz, M., and Holser, W. T.: Permian-Triassic of the Tethys: Carbon isotope studies, Geologische Rundschau, 78, 649-677, 1989.

Baud, A., Cirilli, S., and Marcoux, J.: Biotic response to mas extinction: the lowermost Triasic microbialites, Facies, 36, 238-242, 1997.

Berg, P., Rysgaard, S., and Thamdrup, B.: Dynamic modeling of early diagenesis and nutrient cycling. A case study in an Arctic marine sediment, Am. J. Sci., 303, 905-955, https://doi.org/10.2475/ajs.303.10.905, 2003.

Berner, R. A.: An idealized model of dissolved sulfate distribution in recent sediments, Geochim. Cosmochim. Ac., 28, 1497-1503, https://doi.org/10.1016/0016-7037(64)90164-4, 1964.

Berner, R. A.: Examination of hypotheses for the PermoTriassic boundary extinction by carbon cycle modeling, Proc. Natl. Acad. Sci. USA, 99, 4172-4177, https://doi.org/10.1073/pnas.032095199, 2002.

Berner, R. A., Scott, M. R., and Thomlinson, C.: Carbonate alkalinity in the pore waters of anoxic marine sediments, Limnol. Oceanogr., 15, 544-549, https://doi.org/10.4319/lo.1970.15.4.0544, 1970.

Birgel, D., Meister, P., Lundberg, R., Horath, T. D., Bontognali, T. R. R., Bahniuk, A. M., de Rezende, C. E., Vasconcelos, C., and McKenzie, J. A.: Methanogenesis produces strong ${ }^{13} \mathrm{C}$ enrichment in stromatolites of Lagoa Salgada, Brazil: a modern analogue for Palaeo-/Neoproterozoic stromatolites?, Geobiology, 13, 245-266, https://doi.org/10.1111/gbi.12130, 2015.

Boetius, A., Ravenschlag, K., Schubert, C. J., Rickert, D., Widdel, F., Gieseke, A., Amann, R., Jørgensen, B. B., Witte, U., and Pfannkuche, O.: A marine microbial consortium apparently mediating anaerobic oxidation of methane, Nature, 407, 623-626, https://doi.org/10.1038/35036572, 2000.

Bolker, B. M.: Ecological Models and Data in R, Princeton University Press, 2008.

Bolker, B.: emdbook: Ecological Models and Data in R, available at: https://CRAN.R-project.org/package=emdbook (last access: November 2017), r package version 1.3.9., 2016.

Bontognali, T. R. R., Mckenzie, J. A., Warthmann, R. J., and Vasconcelos, C.: Microbially influenced formation of $\mathrm{Mg}$-calcite and Ca-dolomite in the presence of exopolymeric substances produced by sulphate-reducing bacteria, Terra Nova, 26, 72-77, https://doi.org/10.1111/ter.12072, 2014.

Boudreau, B. P.: On the equivalence of nonlocal and radial-diffusion models for porewater irrigation, J. Mar. Res., 42, 731-735, https://doi.org/10.1357/002224084788505924, 1984.

Boudreau, B. P.: A method-of-lines code for carbon and nutrient diagenesis in aquatic sediments, Comput. Geosci., 22, 479-496, https://doi.org/10.1016/0098-3004(95)00115-8, 1996.

Boudreau, B. P.: Diagenetic models and their implementation. Modelling transport and reactions in aquatic sediments, 3, Springer, New York, https://doi.org/10.I007/97S-3-642-60421-S, 1997.

Boudreau, B. P. and Meysman, F. J. R.: Predicted tortuosity of muds, Geology, 34, 693-696, https://doi.org/10.1130/G22771.1, 2006.

Brand, U. and Veizer, J.: Chemical diagenesis of a multicomponent carbonate system-1: Trace elements, J. Sediment. Res., 
50, 1219-1236, https://doi.org/10.1306/212F7BB7-2B24-11D78648000102C1865D, 1980.

Brand, U. and Veizer, J.: Chemical diagenesis of a multicomponent carbonate system-2: Stable isotopes, J. Sediment. Petrol., 51, 987-997, https://doi.org/10.1306/212F7DF6-2B2411D7-8648000102C1865D, 1981.

Brand, U., Jiang, G., Azmy, K., Bishop, J., and Montañez, I. P.: Diagenetic evaluation of a Pennsylvanian carbonate succession (Bird Spring Formation, Arrow Canyon, Nevada, U.S.A.) - 1: Brachiopod and whole rock comparison, Chem. Geology, 308-309, 2639, https://doi.org/10.1016/j.chemgeo.2012.03.017, 2012a.

Brand, U., Posenato, R., Came, R., Affek, H., Angiolini, L., Azmy, K., and Farabegoli, E.: The end-Permian mass extinction: A rapid volcanic $\mathrm{CO}_{2}$ and $\mathrm{CH}_{4}$ climatic catastrophe, Chem. Geology, 322, 121-144, https://doi.org/10.1016/j.chemgeo.2012.06.015, 2012b.

Brosse, M., Bucher, H., and Goudemand, N.: Quantitative biochronology of the Permian-Triassic boundary in South China based on conodont unitary associations, Earth Sci. Rev., 155, 153-171, https://doi.org/10.1016/j.earscirev.2016.02.003, 2016.

Brown, P. N. and Hindmarsh, A. C.: Reduced storage matrix methods in stiff ODE systems, Appl. Math. Comput., 31, 40-91, https://doi.org/10.1016/0096-3003(89)90110-0, 1989.

Bundeleva, I. A., Shirokova, L. S., Pokrovsky, O. S., Bénézeth, P., Ménez, B., Gérard, E., and Balor, S.: Experimental modeling of calcium carbonate precipitation by cyanobacterium Gloeocapsa sp., Chem. Geology, 374-375, 44-60, https://doi.org/10.1016/j.chemgeo.2014.03.007, 2014.

Busenberg, E. and Plummer, L. N.: Thermodynamics of magnesian calcite solid-solutions at $25^{\circ} \mathrm{C}$ and 1 atm total pressure, Geochim. Cosmochim. Ac., 53, 1189-1208, https://doi.org/10.1016/0016-7037(89)90056-2, 1989.

Canfield, D. E.: Sulfate reduction and oxic respiration in marine sediments: implications for organic carbon preservation in euxinic environments, Deep Sea Res., 36, 121-138, https://doi.org/10.1016/0198-0149(89)90022-8, 1989.

Canfield, D. E., Jørgensen, B. B., Fossing, H., Glud, R., Gundersen, J., Ramsing, N. B., Thamdrup, B., Hansen, J. W., Nielsen, L. P., and Hall, P. O.: Pathways of organic carbon oxidation in three continental margin sediments, Mar. Geology, 113, 27-40, https://doi.org/10.1016/0025-3227(93)90147-N, 1993.

Cao, C., Wang, W., and Jin, Y.: Carbon isotope excursions across the Permian-Triassic boundary in the Meishan section, Zhejiang Province, China, Chinese Sci. B., 47, 1125-1129, https://doi.org/10.1360/02tb9252, 2002.

Cao, C., Love, G. D., Hays, L. E., Wang, W., Shen, S., and Summons, R. E.: Biogeochemical evidence for euxinic oceans and ecological disturbance presaging the end-Permian mass extinction event, Earth Planet. Sci. Lett., 281, 188-201, https://doi.org/10.1016/j.eps1.2009.02.012, 2009.

Chen, J.-S., Chu, X.-L., Shao, M.-R., and Zhong, H.: Carbon isotope study of the Permian-Triassic boundary sequences in China, Chem. Geology: Isotope Geoscience Section, 86, 239251, https://doi.org/10.1016/0168-9622(91)90052-X, 1991.

Clarkson, M. O., Kasemann, S. A., Wood, R. A., Lenton, T. M., Daines, S. J., Richoz, S., Ohnemueller, F., Meixner, A., Poulton, S. W., and Tipper, E. T.: Ocean acidification and the Permo-Triassic mass extinction, Science, 348, 229-232, https://doi.org/10.1126/science.aaa0193, 2015.
Contreras, S., Meister, P., Liu, B., Prieto-mollar, X., Hinrichs, K.-u., and Khalili, A.: subsea floor redox zonation on the Peruvian shelf, Proc. Natl. Acad. Sci., 110, 1-6, https://doi.org/10.1073/pnas.1305981110, 2013.

Dale, A. W., Boyle, R. A., Lenton, T. M., Ingall, E. D., and Wallmann, K.: A model for microbial phosphorus cycling in bioturbated marine sediments: Significance for phosphorus burial in the early Paleozoic, Geochim. Cosmochim. Ac., 189, 251-268, https://doi.org/10.1016/j.gca.2016.05.046, 2016.

Dickens, G. R., O'Neil, J. R., Rea, D. K., and Owen, R. M.: Dissociation of oceanic methane hydrate as a cause of the carbon isotope excursion at the end of the Paleocene, Paleoceanography, 10, 965-971, https://doi.org/10.1029/95PA02087, 1995.

Emrich, K., Ehhalt, D. H., and Vogel, J. C.: Carbon isotope fractionation during the precipitation of calcium carbonate, Earth Planet. Sci. Lett., 8, 363-371, https://doi.org/10.1016/0012821X(70)90109-3, 1970.

Erwin, D. H.: The great Paleozoic crisis. Life and Death in the Permian, Columbia University Press, New York, 1993.

Fantle, M. S. and DePaolo, D. J.: Sr isotopes and pore fluid chemistry in carbonate sediment of the Ontong Java Plateau: Calcite recrystallization rates and evidence for a rapid rise in seawater $\mathrm{Mg}$ over the last 10 million years, Geochim. Cosmochim. Ac., 70, 3883-3904, https://doi.org/10.1016/j.gca.2006.06.009, 2006.

Fantle, M. S. and DePaolo, D. J.: Ca isotopes in carbonate sediment and pore fluid from ODP Site 807A: The $\mathrm{Ca}_{(\mathrm{aq})}^{2+}$-calcite equilibrium fractionation factor and calcite recrystallization rates in Pleistocene sediments, Geochim. Cosmochim. Ac., 71, 2524 2546, https://doi.org/10.1016/j.gca.2007.03.006, 2007.

Flügel, E.: Microfacies of Carbonate Rocks, Springer-Verlag, Berlin Heidelberg, 2nd edn., https://doi.org/10.1007/978-3-662-087268, 2010.

Fossing, H., Berg, P., Thamdrup, B., Rysgaard, S., and Munk, H.: A model set-up for an oxygen and nutrient flux model for Aarhus Bay (Denmark), 483, National Environmental Research Institute, available at: http://www.2.dmu.dk/1_Viden/2_ Publikationer/3_fagrapporter/rapporter/FR483.PDF (last access: November 2017), 2004.

Froelich, P. N., Klinkhammer, G. P., Bender, M. L., Luedtke, N. A., Heath, G. R., Cullen, D., Dauphin, P., Hammond, D., Hartman, B., and Maynard, V.: Early oxidation of organic matter in pelagic sediments of the eastern equatorial Atlantic: suboxic diagenesis, Geochim. Cosmochim. Ac., 43, 1075-1090, https://doi.org/10.1016/0016-7037(79)90095-4, 1979.

Garcia-Pichel, F., Al-Horani, F. A., Farmer, J. D., Ludwig, R., and Wade, B. D.: Balance between microbial calcification and metazoan bioerosion in modern stromatolitic oncolites, Geobiology, 2, 49-57, https://doi.org/10.1111/j.14724669.2004.00017.x, 2004.

Grice, K., Cao, C., Love, G. D., Böttcher, M. E., Twitchett, R. J., Grosjean, E., Summons, R. E., Turgeon, S. C., Dunning, W., and Jin, Y.: Photic zone euxinia during the Permian-Triassic superanoxic event, Science, 307, 706-9, https://doi.org/10.1126/science.1104323, 2005.

Gruszczyński, M., Małkowski, K., Szaniawski, H., and ChengYuan, W.: The carbon biogeochemical cycle across the PermianTriassic boundary strata and its implications: Isotope record from the Changhsingian Stage at Meishan, south China, Acta Geologica Polonica, 53, 167-179, 2003. 
Heindel, K., Richoz, S., Birgel, D., Brandner, R., Klügel, A., Krystyn, L., Baud, A., Horacek, M., Mohtat, T., and Peckmann, J.: Biogeochemical formation of calyx-shaped carbonate crystal fans in the subsurface of the Early Triassic seafloor, Gondwana Research, https://doi.org/10.1016/j.gr.2013.11.004, 2013.

Hermann, E., Hochuli, P. A., Bucher, H., Vigran, J. O., Weissert, H., and Bernasconi, S. M.: A close-up view of the Permian-Triassic boundary based on expanded organic carbon isotope records from Norway (Trøndelag and Finnmark Platform), Global Planet. Change, 74, 156-167, https://doi.org/10.1016/j.gloplacha.2010.10.007, 2010.

Heydari, E., Hassandzadeh, J., and Wade, W. J.: Geochemistry of central tethyan Upper Permian and Lower Triassic strata, Abadeh region, Iran, Sediment. Geol., 137, 85-99, https://doi.org/10.1016/S0037-0738(00)00138-X, 2000.

Heydari, E., Wade, W. J., and Hassanzadeh, J.: Diagenetic origin of carbon and oxygen isotope compositions of PermianTriassic boundary strata, Sediment. Geol., 143, 191-197, https://doi.org/10.1016/S0037-0738(01)00095-1, 2001.

Heydari, E., Arzani, N., and Hassanzadeh, J.: Mantle plume: The invisible serial killer - Application to the Permian-Triassic boundary mass extinction, Palaeogeogr. Palaeoclimatol. Palaeoecol., 264, 147-162, https://doi.org/10.1016/j.palaeo.2008.04.013, 2008.

Heydari, E., Arzani, N., Safaei, M., and Hassanzadeh, J.: Ocean's response to a changing climate: Clues from variations in carbonate mineralogy across the Permian-Triassic boundary of the Shareza Section, Iran, Global Planet. Change, 105, 79-90, https://doi.org/10.1016/j.gloplacha.2012.12.013, 2013.

Hoffman, A., Gruszczynskj, M., Malkowskj, K., and Wski, H. S.: Should the Permian/Triassic boundary be defined by the carbon isotope shift?, Acta Geologica Polonica, 48, 141-148, 1998.

Hofmann, R., Buatois, L., MacNaughton, R., and Mángano, M.: Loss of the sedimentary mixed layer as a result of the endPermian extinction, Palaeogeogr. Palaeoclimatol. Palaeoecol., 428, 1-11, https://doi.org/10.1016/j.palaeo.2015.03.036, 2015.

Horacek, M., Richoz, S., Brandner, R., Krystyn, L., and Spötl, C.: Evidence for recurrent changes in Lower Triassic oceanic circulation of the Tethys: The $\delta^{13} \mathrm{C}$ record from marine sections in Iran, Palaeogeogr. Palaeoclimatol. Palaeoecol., 252, 355-369, https://doi.org/10.1016/j.palaeo.2006.11.052, 2007.

Hsiang, S. M.: Visually-Weighted Regression, available at: http: //www.fight-entropy.com/2012/08/watercolor-regression.html (last access: 2016), 2012.

Huang, J., Luo, G., Bai, X., and Tang, X.: Organic fraction of the total carbon burial flux deduced from carbon isotopes across the Permo-Triassic boundary at Meishan, Zhejiang Province, China, Frontiers of Earth Science in China, 1, 425430, https://doi.org/10.1007/s11707-007-0052-z, 2007.

Irwin, H., Curtis, C., and Coleman, M.: Isotopic evidence for source of diagenetic carbonates formed during burial of organic-rich sediments, Nature, 269, 209-213, https://doi.org/10.1038/269209a0, 1977.

James, N. and Choquette, P.: Limestones: introduction, in: Diagenesis, 5, 159-161, Geoscience Canada, 1983.

Jin, Y., Wang, Y., Wang, W., Shang, Q., Cao, C., and Erwin, D.: Pattern of marine mass extinction near the PermianTriassic boundary in South China, Science, 289, 432-436, https://doi.org/10.1126/science.289.5478.432, 2000.
Kaiho, K., Kajiwara, Y., Chen, Z.-Q., and Gorjan, P.: A sulfur isotope event at the end of the Permian, Chem. Geol., 235, 33-47, https://doi.org/10.1016/j.chemgeo.2006.06.001, 2006.

Kakuwa, Y. and Matsumoto, R.: Cerium negative anomaly just before the Permian and Triassic boundary event The upward expansion of anoxia in the water column, Palaeogeogr. Palaeoclimatol. Palaeoecol., 229, 335-344, https://doi.org/10.1016/j.palaeo.2005.07.005, 2006.

Kershaw, S., Li, Y., Crasquin-soleau, S., Feng, Q., Mu, X., Collin, P.-Y., Reynolds, A., and Guo, L.: Earliest Triassic microbialites in the South China block and other areas: controls on their growth and distribution, Facies, 53, 409-425, https://doi.org/10.1007/s10347-007-0105-5, 2007.

Kershaw, S., Crasquin, S., Collin, P.-Y., Li, Y., Feng, Q., and Forel, M.-B.: Microbialites as disaster forms in anachronistic facies following the end-Permian mass extinction: a discussion, Aust. J. Earth Sci., 56, 809-813, https://doi.org/10.1080/08120090903002623, 2009.

Knauth, L. P. and Kennedy, M. J.: The late Precambrian greening of the Earth, Nature, 460, 728-32, https://doi.org/10.1038/nature08213, 2009.

Knoll, A. H., Bambach, R. K., Canfield, D. E., and Grotzinger, J. P.: Comparative Earth history and Late Permian mass extinction, Science, 273, 452-457, https://doi.org/10.1126/science.273.5274.452, 1996.

Knoll, A. H., Bambach, R. K., Payne, J. L., Pruss, S., and Fischer, W. W.: Paleophysiology and end-Permian mass extinction, Earth Planet. Sci. Lett., 256, 295-313, https://doi.org/10.1016/j.epsl.2007.02.018, 2007.

Korte, C. and Kozur, H. W.: Carbon isotope stratigraphy across the Permian/Triassic at Jolfa (NW-Iran, Peitlerkofel (Sas de Pütia, Sass de Putia, Pufels (Bula, Bulla), Tesero (all three Southern Alps Italy) and Gerennavár (Bükk Mts., Hungary), J. Alpine Geol., 47, 119-135, 2005.

Korte, C., Kozur, H. W., Joachimski, M. M., Strauss, H., Veizer, J., and Schwark, L.: Carbon, sulfur, oxygen and strontium isotope records, organic geochemistry and biostratigraphy across the Permian/Triassic boundary in Abadeh, Iran, Int. J. Earth Sci., 93, 565-581, https://doi.org/10.1007/s00531-004-0406-7, 2004a.

Korte, C., Kozur, H., and Mohtat-Aghai, P.: Dzhulfian to lowermost Triassic $\delta^{13} \mathrm{C}$ record at the Permian/Triassic boundary section at Shahreza, Central Iran, Hallesches Jahrbuch Geowissenschaften, Reihe B, 18, 73-78, 2004b.

Korte, C., Kozur, H. W., and Partoazar, H.: Negative carbon isotope excursion at the Permian/Triassic boundary section at Zal, NWIran, Hallesches Jahrbuch Geowissenschaften, Reihe B, Beiheft 18, 69-71, 2004c.

Korte, C., Jasper, T., Kozur, H. W., and Veizer, J.: $\delta^{18} \mathrm{O}$ and $\delta^{13} \mathrm{C}$ of Permian brachiopods: A record of seawater evolution and continental glaciation, Palaeogeogr. Palaeoclimatol. Palaeoecol., 224, 333-351, https://doi.org/10.1016/j.palaeo.2005.03.015, 2005.

Korte, C., Pande, P., Kalia, P., Kozur, H. W., Joachimski, M. M., and Oberhänsli, H.: Massive volcanism at the Permian-Triassic boundary and its impact on the isotopic composition of the ocean and atmosphere, J. Asian Earth Sci., 37, 293-311, https://doi.org/10.1016/j.jseaes.2009.08.012, 2010.

Kristensen, E., Penha-Lopes, G., Delefosse, M., Valdemarsen, T., Quintana, C. O., and Banta, G. T.: What is bioturbation? the need for a precise definition for fauna in 
aquatic sciences, Mar. Ecol. Progress Series, 446, 285-302, https://doi.org/10.3354/meps09506, 2012.

Krull, E. S. and Retallack, G. J.: $\delta^{13} \mathrm{C}$ depth profiles from paleosols across the Permian-Triassic boundary: Evidence for methane release, Bull. Geol. Soc. Am., 112, 1459-1472, https://doi.org/10.1130/00167606(2000)112<1459:CDPFPA>2.0.CO;2, 2000.

Kump, L. R. and Arthur, M. A.: Interpreting carbon-isotope excursions: carbonates and organic matter, Chem. Geol., 161, 181198, https://doi.org/10.1016/S0009-2541(99)00086-8, 1999.

Leda, L., Korn, D., Ghaderi, A., Hairapetian, V., Struck, U., and Reimold, W. U.: Lithostratigraphy and carbonate microfacies across the Permian-Triassic boundary near Julfa (NW Iran) and in the Baghuk Mountains (Central Iran), Facies, 60, 295-325, https://doi.org/10.1007/s10347-013-0366-0, 2014.

Li, M., Ogg, J., Zhang, Y., Huang, C., Hinnov, L., Chen, Z.-Q., and Zou, Z.: Astronomical tuning of the endPermian extinction and the Early Triassic Epoch of South China and Germany, Earth Planet. Sci. Lett., 441, 10-25, https://doi.org/10.1016/j.epsl.2016.02.017, 2016.

Li, R. and Jones, B.: Diagenetic overprint on negative $\delta^{13} \mathrm{C}$ excursions across the Permian/Triassic boundary: A case study from Meishan section, China, Palaeogeogr. Palaeoclimatol. Paleoecol., 468, 18-33, https://doi.org/10.1016/j.palaeo.2016.11.044, 2017.

Liu, X.-C., Wang, W., Shen, S.-Z., Gorgij, M. N., Ye, F.C., Zhang, Y.-C., Furuyama, S., Kano, A., and Chen, X.-Z.: Late Guadalupian to Lopingian (Permian) carbon and strontium isotopic chemostratigraphy in the Abadeh section, central Iran, Gondwana Research, 24, 222-232, https://doi.org/10.1016/j.gr.2012.10.012, 2013.

Luo, G., Kump, L. R., Wang, Y., Tong, J., Arthur, M. A., Yang, H., Huang, J., Yin, H., and Xie, S.: Isotopic evidence for an anomalously low oceanic sulfate concentration following endPermian mass extinction, Earth Planet. Sci. Lett., 300, 101-111, https://doi.org/10.1016/j.epsl.2010.09.041, 2010.

Marshall, J. D.: Climatic and oceanographic isotopic signals from the carbonate rock record and their preservation, Geology Magazine, 129, 143-160, https://doi.org/10.1017/S0016756800008244, 1992.

Mayhew, P. J., Bell, M. A., Benton, T. G., and McGowan, A. J.: Biodiversity tracks temperature over time, Proc. Natl. Acad. Sci. USA, 109, 15141-5, https://doi.org/10.1073/pnas.1200844109, 2012.

Melim, L., Swart, P., Munnecke, a., Eberli, G., and Westphal, H.: Questioning carbonate diagenetic paradigms: evidence from the Neogene of the Bahamas, Mar. Geol., 185, 27-53, https://doi.org/10.1016/S0025-3227(01)00289-4, 2002.

Meyer, K., Kump, L., and Ridgwell, A.: Biogeochemical controls on photic-zone euxinia during the end-Permian mass extinction, Geology, 36, 747, https://doi.org/10.1130/G24618A.1, 2008.

Meyer, K., Yu, M., Jost, A. B., Kelley, B., and Payne, J.: $\delta^{13} \mathrm{C}$ evidence that high primary productivity delayed recovery from endPermian mass extinction, Earth Planet. Sci. Lett., 302, 378-384, https://doi.org/10.1016/j.epsl.2010.12.033, 2011.

Meysman, F. J., Middelburg, J. J., Herman, P. M., and Heip, C. H.: Reactive transport in surface sediments. II. Media: an objectoriented problem-solving environment for early diagenesis,
Comput. Geosci., 29, 301-318, https://doi.org/10.1016/S00983004(03)00007-4, 2003.

Meysman, F. J. R., Boudreau, B. P., and Middelburg, J. J.: When and why does bioturbation lead to diffusive mixing?, J. Marine Res., 68, 881-920, https://doi.org/10.1357/002224010796673885, 2010.

Meysman, F. J. R., Risgaard-Petersen, N., Malkin, S. Y., and Nielsen, L. P.: The geochemical fingerprint of microbial longdistance electron transport in the seafloor, Geochim. Cosmochim. Ac., 152, 122-142, https://doi.org/10.1016/j.gca.2014.12.014, 2015.

Müller, P. J. and Suess, E.: Productivity, sedimentation rate, and sedimentary organic matter in the oceans-I. Organic carbon preservation, Deep Sea Res. Part A, 26, 1347-1362, https://doi.org/10.1016/0198-0149(79)90003-7, 1979.

Munnecke, A. and Samtleben, C.: The formation of micritic limestones and the development of limestone-marl alternations in the Silurian of Gotland, Sweden, Facies, 34, 159-176, https://doi.org/10.1007/BF02546162, 1996.

Payne, J. L., Turchyn, A. V., Paytan, A., Depaolo, D. J., Lehrmann, D. J., Yu, M., and Wei, J.: Calcium isotope constraints on the end-Permian mass extinction, Proc. Natl. Acad. Sci. USA, 107, 8543-8548, https://doi.org/10.1073/pnas.0914065107, 2010.

Prokoph, A., Shields, G. A., and Veizer, J.: Compilation and timeseries analysis of a marine carbonate $\delta^{18} \mathrm{O}, \delta^{13} \mathrm{C},{ }^{87} \mathrm{Sr} /{ }^{86} \mathrm{Sr}$ and $\delta^{34} \mathrm{~S}$ database through Earth history, Earth Sci. Rev., 87, 113133, https://doi.org/10.1016/j.earscirev.2007.12.003, 2008.

Pruss, S. B., Bottjer, D. J., Corsetti, F. A., and Baud, A.: A global marine sedimentary response to the endPermian mass extinction: Examples from southern Turkey and the western United States, Earth Sci. Rev., 78, 193-206, https://doi.org/10.1016/j.earscirev.2006.05.002, 2006.

Rampino, M. R. and Caldeira, K.: Major perturbation of ocean chemistry and a "Strangelove Ocean" after the end-Permian mass extinction, Terra Nova, 17, 554-559, https://doi.org/10.1111/j.1365-3121.2005.00648.x, 2005.

R Core Team: R: A Language and Environment for Statistical Computing, available at: https://www.r-project.org (last access: November 2017), 2016.

Reimers, C. E. and Suess, E.: The partitioning of organic carbon fluxes and sedimentary organic matter decomposition in the ocean, Mar. Chem., 13, 141-168, https://doi.org/10.1016/03044203(83)90022-1, 1983.

Reitner, J., Peckmann, J., Reimer, A., Schumann, G., and Thiel, V.: Methane-derived carbonate build-ups and associated microbial communities at cold seeps on the lower Crimean shelf (Black Sea), Facies, 51, 66-79, https://doi.org/10.1007/s10347005-0059-4, 2005.

Renne, P. R., Black, M. T., Zichao, Z., Richards, M. A., and Basu, A. R.: Synchrony and causal relations between PermianTriassic boundary crises and siberian flood volcanism, Science, 269, 1413-1416, https://doi.org/10.1126/science.269.5229.1413, 1995.

Retallack, G. J. and Jahren, A. H.: Methane Release from Igneous Intrusion of Coal during Late Permian Extinction Events, The Journal of Geology, 116, 1-20, https://doi.org/10.1086/524120, 2008.

Riccardi, A., Kump, L. R., Arthur, M. A., and D’Hondt, S.: Carbon isotopic evidence for chemocline upward excursions during the 
end-Permian event, Palaeogeogr. Palaeoclimatol. Palaeoecol., 248, 73-81, https://doi.org/10.1016/j.palaeo.2006.11.010, 2007.

Richoz, S., Krystyn, L., Baud, A., Brandner, R., Horacek, M., and Mohtat-Aghai, P.: Permian-Triassic boundary interval in the Middle East (Iran and N. Oman): Progressive environmental change from detailed carbonate carbon isotope marine curve and sedimentary evolution, J. Asian Earth Sci., 39, 236-253, https://doi.org/10.1016/j.jseaes.2009.12.014, 2010.

Ridgwell, A.: A Mid Mesozoic Revolution in the regulation of ocean chemistry, Mar. Geol., 217, 339-357, https://doi.org/10.1016/j.margeo.2004.10.036, 2005.

Riding, R. and Liang, L.: Geobiology of microbial carbonates: metazoan and seawater saturation state influences on secular trends during the Phanerozoic, Palaeogeogr. Palaeoclimatol. Palaeoecol., 219, 101-115, https://doi.org/10.1016/j.palaeo.2004.11.018, 2005.

Ries, J. B., Anderson, M. A., and Hill, R. T.: Seawater $\mathrm{Mg} / \mathrm{Ca}$ controls polymorph mineralogy of microbial $\mathrm{CaCO}_{3}$ : A potential proxy for calcite-aragonite seas in Precambrian time, Geobiology, 6, 106-119, https://doi.org/10.1111/j.14724669.2007.00134.x, 2008.

Rothman, D. H., Fournier, G. P., French, K. L., Alm, E. J., Boyle, E. A., Cao, C., and Summons, R. E.: Methanogenic burst in the end-Permian carbon cycle, Proc. Natl. Acad. Sci. USA, 111, 5462-7, https://doi.org/10.1073/pnas.1318106111, 2014.

Saltzman, M. R.: Late Paleozoic ice age; Oceanic gateway or p $\mathrm{CO}_{2}$ ?, Geology, 31, 151-154, https://doi.org/10.1130/00917613(2003)031<0151:LPIAOG>2.0.CO;2, 2001.

Sarmiento, J. L. and Gruber, N.: Calcium carbonate cycling, in: Ocean Biogeochemical Dynamics, chap. 9, 1-44, Princeton University Press, New York, available at: http://press.princeton.edu/ titles/8223.html (last access: 2016), 2004.

Schobben, M.: carbonate project, https://doi.org/10.5281/zenodo.888754, available at: https://github.com/MartinSchobben/carbonate, https: //github.com/MartinSchobben/carbonate, last access: 2017.

Schobben, M., Joachimski, M. M., Korn, D., Leda, L., and Korte, C.: Palaeotethys seawater temperature rise and an intensified hydrological cycle following the endPermian mass extinction, Gondwana Research, 26, 675-683, https://doi.org/10.1016/j.gr.2013.07.019, 2014.

Schobben, M., Stebbins, A., Ghaderi, A., Strauss, H., Korn, D., and Korte, C.: Flourishing ocean drives the end-Permian marine mass extinction, Proc. Natl. Acad. Sci., 112, 10298-10303, https://doi.org/10.1073/pnas.1503755112, 2015.

Schobben, M., Ullmann, C. V., Leda, L., Korn, D., Struck, U., Reimold, W. U., Ghaderi, A., Algeo, T. J., and Korte, C.: Discerning primary versus diagenetic signals in carbonate carbon and oxygen isotope records: An example from the Permian-Triassic boundary of Iran, Chem. Geol., 422, 94-107, https://doi.org/10.1016/j.chemgeo.2015.12.013, 2016.

Schobben, M., Stebbins, A., Algeo, T. J., Strauss, H., Leda, L., Haas, J., Struck, U., Korn, D., and Korte, C.: Volatile earliest Triassic sulfur cycle: A consequence of persistent low seawater sulfate concentrations and a high sulfur cycle turnover rate?, Palaeogeogr. Palaeoclimatol. Palaeoecol., https://doi.org/10.1016/j.palaeo.2017.02.025, 2017.
Schönbrodt, F.: Visually weighted/Watercolor Plots, new variants: Please vote!, available at: http://www.nicebread.de/ (last access: 2016), 2012.

Schrag, D. P., Higgins, J. A., Macdonald, F. A., and Johnston, D. T.: Authigenic carbonate and the history of the global carbon cycle, Science, 339, 540-543, https://doi.org/10.1126/science.1229578, 2013.

Soetaert, K. and Meysman, F.: Reactive transport in aquatic ecosystems: Rapid model prototyping in the open source software R, Environ. Model. Softw., 32, 49-60, https://doi.org/10.1016/j.envsoft.2011.08.011, 2012.

Soetaert, K., Herman, P. M. J., and Middelburg, J. J.: A model of early diagenetic processes from the shelf to abyssal depths, Geochim. Cosmochim. Ac., 60, 1019-1040, https://doi.org/10.1016/0016-7037(96)00013-0, 1996.

Soetaert, K., Petzoldt, T., and Setzer, R.: Package deSolve: solving initial value differential equations in R, J. Stat. Softw., 33, 1-25, https://doi.org/10.18637/jss.v033.i09, 2010.

Soetaert, K., Petzoldt, T., and Meysman, F.: marelac: Tools for Aquatic Sciences, available at: https://CRAN.R-project.org/ package $=$ marelac (last access: November 2017), r package version 2.1.6, 2016.

Song, H., Tong, J., Algeo, T. J., Horacek, M., Qiu, H., Song, H., Tian, L., and Chen, Z. Q.: Large vertical $\delta^{13} C_{\text {DIC }}$ gradients in Early Triassic seas of the South China craton: Implications for oceanographic changes related to Siberian Traps volcanism, Global Planet. Change, 105, 7-20, https://doi.org/10.1016/j.gloplacha.2012.10.023, 2013.

Song, H., Tong, J., Algeo, T. J., Song, H., Qiu, H., Zhu, Y., Tian, L., Bates, S., Lyons, T. W., Luo, G., and Kump, L. R.: Early Triassic seawater sulfate drawdown, Geochim. Cosmochim. Ac., 128, 95-113, https://doi.org/10.1016/j.gca.2013.12.009, 2014.

Svensen, H., Planke, S., Polozov, A. G., Schmidbauer, N., Corfu, F., Podladchikov, Y. Y., and Jamtveit, B.: Siberian gas venting and the end-Permian environmental crisis, Earth Planet. Sci. Lett., 277, 490-500, https://doi.org/10.1016/j.epsl.2008.11.015, 2009.

Ullrich, T. S.: xyscan, available at: http://rhig.physics.yale.edu/ ullrich/software/xyscan/ (last access: 2016), 2016.

Van Cappellen, P. and Wang, Y.: Cycling of iron and manganese in surface sediments: A general theory for the coupled transport and reaction of carbon, oxygen, nitrogen, sulfur, iron, and manganese, Am. J. Sci., 296, 197-243, https://doi.org/10.2475/ajs.296.3.197, 1996.

van de Velde, S. and Meysman, F. J.: The influence of bioturbation on iron and sulphur cycling in marine sediments: a model analysis, Aquat. Geochem., 22, 469-504, https://doi.org/10.1007/s10498-016-9301-7, 2016.

Veizer, J., Ala, D., Azmy, K., Bruckschen, P., Buhl, D., Bruhn, F., Carden, G. A. F., Diener, A., Ebneth, S., Godderis, Y., Jasper, T., Korte, C., Pawellek, F., Podlaha, O. G., and Strauss, H.: ${ }^{87} \mathrm{Sr} /{ }^{86} \mathrm{Sr}, \delta^{13} \mathrm{C}$ and $\delta^{18} \mathrm{O}$ evolution of Phanerozoic seawater, Chem. Geol., 161, 59-88, https://doi.org/10.1016/S00092541(99)00081-9, 1999.

Visscher, P. T., Reid, P. R., and Bebout, B. M.: Microscale observations of sulfate reduction: Correlation of microbial activity with lithified micritic laminae in modern marine stromatolites, Geology, 28, 919-922, https://doi.org/10.1130/00917613(2000)28<919:MOOSRC>2.0.CO, 2000. 
Wacey, D., Wright, D. T., and Boyce, A. J.: A stable isotope study of microbial dolomite formation in the Coorong Region, South Australia, Chem. Geol., 244, 155-174, https://doi.org/10.1016/j.chemgeo.2007.06.032, 2007.

Wang, Y., Sadler, P. M., Shen, S. Z., Erwin, D. H., Zhang, Y. C., Wang, X. D., Wang, W., Crowley, J. L., and Henderson, C. M.: Quantifying the process and abruptness of the end-Permian mass extinction, Paleobiology, 40, 113-129, https://doi.org/10.1666/13022, 2014.

Wickham, H.: Reshaping Data with the reshape Package, J. Stat. Softw., 21, 1-20, 2007.

Wickham, H.: ggplot2: Elegant Graphics for Data Analysis, Springer-Verlag New York, available at: http://ggplot2.org (last access: 2017), 2009.

Wickham, H.: The Split-Apply-Combine Strategy for Data Analysis, J. Stat. Softw., 40, 1-29, 2011.

Wignall, P. B. and Twitchett, R. J.: Oceanic anoxia and the End Permian mass extinction, Science, 272, 1155-1158, https://doi.org/10.1126/science.272.5265.1155, 1996.

Winguth, A. M. E., Shields, C. A., and Winguth, C.: Transition into a Hothouse World at the Permian-Triassic boundaryA model study, Palaeogeogr. Palaeocl., 440, 316-327, https://doi.org/10.1016/j.palaeo.2015.09.008, 2015.

Woods, A. D., Bottjer, D. J., Mutti, M., and Morrison, J.: Lower Triassic large sea-floor carbonate cements: Their origin and a mechanism for the prolonged biotic recovery from the end-Permian mass extinction, Geology, 27, 645, https://doi.org/10.1130/00917613(1999)027<0645:LTLSFC>2.3.CO;2, 1999.
Xie, S., Pancost, R. D., Huang, J., Wignall, P. B., Yu, J., Tang, X., Chen, L., Huang, X., and Lai, X.: Changes in the global carbon cycle occurred as two episodes during the Permian-Triassic crisis, Geology, 35, 1083-1086, https://doi.org/10.1130/G24224A.1, 2007.

$\mathrm{Xu}, \mathrm{D} .-\mathrm{Y}$. and Yan, Z.: Carbon isotope and iridium event markers near the Permian-Triassic boundary in the Meishan section, Zhejiang Province, China, Palaeogeogr. Palaeoclimatol. Palaeoecol., 104, 171-176, https://doi.org/10.1016/0031-0182(93)90128-6, 1993.

Yin, H., Jiang, H., Xia, W., Feng, Q., Zhang, N., and Shen, J.: The end-Permian regression in South China and its implication on mass extinction, Earth Sci. Rev., 137, 19-33, https://doi.org/10.1016/j.earscirev.2013.06.003, 2014.

Zachos, J., Pagani, M., Sloan, L., Thomas, E., and Billups, K.: Trends, rhythms, and aberrations in global climate 65Ma to present, Science, 292, 686-693, https://doi.org/10.1126/science.1059412, 2001.

Zeebe, R. E. and Westbroek, P.: A simple model for the $\mathrm{CaCO}_{3}$ saturation state of the ocean; the "Strangelove," the "Neritan," and the "Cretan" ocean, Geochem. Geophys. Geosyst., 4, 1-26, https://doi.org/10.1029/2003GC000538, 2003.

Zhao, M.-Y., Zheng, Y.-F., and Zhao, Y.-Y.: Seeking a geochemical identifier for authigenic carbonate, Nature Comm., 7, 10885, https://doi.org/10.1038/ncomms10885, 2016.

Zuo, J.-X., Tong, J.-N., Qiu, H.-o., and Zhao, L.-S.: Carbon isotope composition of the Lower Triassic marine carbonates, Lower Yangtze Region, South China, Science in China Series D: Earth Sciences, 49, 225-241, https://doi.org/10.1007/s11430006-0225-8, 2006. 